\title{
Base Isolation for Seismic Retrofitting of a Multiple Building Structure: Design, Construction, and Assessment
}

\author{
Massimiliano Ferraioli and Alberto Mandara \\ Department of Civil Engineering, Design, Building and Environment, Second University of Naples, Via Roma 29, \\ Aversa, 81031 Campania, Italy
}

Correspondence should be addressed to Massimiliano Ferraioli; massimiliano.ferraioli@unina2.it

Received 22 April 2016; Revised 21 July 2016; Accepted 16 October 2016; Published 22 January 2017

Academic Editor: Alessandro Palmeri

Copyright ( 2017 Massimiliano Ferraioli and Alberto Mandara. This is an open access article distributed under the Creative Commons Attribution License, which permits unrestricted use, distribution, and reproduction in any medium, provided the original work is properly cited.

\begin{abstract}
The paper deals with the seismic retrofit of a multiple building structure belonging to the Hospital Centre of Avellino (Italy). At first, the paper presents the preliminary investigations, the in situ measurements and laboratory tests, and the seismic assessment of the existing fixed-base structures. Having studied different strategies, base isolation proved to be the more appropriate, also for the possibility offered by the geometry of the building to easily create an isolation interface at the ground level. The paper presents the design project, the construction process, and the details of the isolation intervention. Some specific issues of base isolation for seismic retrofitting of multiple building structures were lightened. Finally, the seismic assessment of the base-isolated building was carried out. The seismic response was evaluated through nonlinear time-history analysis, using the well-known Bouc-Wen model as the constitutive law of the isolation bearings. For reliable dynamic analyses, a suite of natural accelerograms compatible with acceleration spectra of Italian Code was first selected and then applied along both horizontal directions. The results were finally used to address some of the critical issues of the seismic response of the base-isolated multiple building structure: accidental torsional effects and potential poundings during strong earthquakes.
\end{abstract}

\section{Introduction}

A new interest in seismic isolation in Italy was created by some strong earthquakes (Umbria-Marche, 1997; MolisePuglia, 2002; Abruzzo 2009; Emilia, 2012) as well as the publishing of the new Italian Code [1]. The evolution of seismic codes in Italy after the recent Italian earthquakes led to a general increase of the design seismic actions. Nowadays, many strategic buildings cannot resist strong earthquakes that, however, may occur many times during its lifetime since the return period of the design seismic event is very long. On the other hand, the Italian Code [1], like the Eurocode 8 [2], now contains two chapters devoted to the seismic isolation of buildings and bridges. This situation produced a significant effect in promoting the general application of seismic isolation not only to schools, hospitals, and emergency management centres but also to ordinary residential and commercial buildings. Many studies in the literature focused on the performance of buildings protected by isolators, either made of rubber (elastomeric bearings with or without lead cores) [3-6] or based on sliding surfaces (friction-pendulum type bearings). Originally proposed by Zayas et al. [7], the friction-pendulum system (FPS) was extended to devices with multiple independent mechanisms. A first generation of friction concave isolators consisted of a spherical concave sliding surface that produces a constant vibration period for the isolated structure depending on the curvature radius of the sliding surface. Multiple pendulums bearings such as Double and Triple Friction Pendulum (DFP and TFP) were developed in such a way to exhibit adaptive behavior under different hazard level of earthquakes owing to multiple sliding surfaces. In fact, in spite of being fully passive device, these bearings allow choosing a desirable combination of stiffness and damping in certain levels of excitation, simply selecting the radii of curvature, the friction coefficients, and the displacement capacities of each concave surface [8-12]. Jangid [13] investigated the analytical seismic response of multistorey buildings isolated by the frictionpendulum system (FPS) under near-fault motions. Tsai et al. 
[14] proposed an advanced analytical model based on the viscoplasticity theory and rigorous finite element derivations for the Multiple Friction-Pendulum System. Becker and Mahin [15] developed complex models capable of simulating the bidirectional shear behavior of TFP isolators. Nowadays, the advantages of seismic isolation compared to conventional strengthening methods are universally recognized. These methods generally include adding new structural elements and enlarging the existing members. The addition of shear walls and bracings is the most popular strengthening method due to its effectiveness and lower overall project cost compared to the column and beam jacketing. However, the typical effect of these conventional strengthening methods is the increase in both the stiffness and the lateral load capacity of the structure. As stiffness increases so does the strength, this approach leads to larger mechanism forces in nonductile members and foundations. Furthermore, due to the increased stiffness, which translates into a decreased fundamental period, the seismic demand on the structure is also increased. In fact, the period shortening of the structure generally increases the seismic demand except in the case of low-rise buildings that fail in the constant-acceleration region of the response spectrum. Thus, the capacity increase is partly alleviated by the increase in seismic demand, and the overall performance of the structure is improved slightly. As an alternative, seismic isolation and supplemental energy dissipation are recognized as the two main effective methods to reducing the dynamic responses of structures when subjected to earthquakes without increasing their global stiffness. Base isolation [16] lengthens the natural period of the structure away from the predominant frequency of the ground motions. Thus, it reduces the transmitted acceleration into the superstructure that is the part of the structure which is isolated and is located above the isolation interface. Supplemental energy dissipation devices were shown effective in reducing the building deformation response through increasing the structure's effective damping. This not only provides safety against collapse but also largely reduces damage, which is fundamental for facilities that should remain operational after severe earthquakes such as emergency centres, fire stations, and hospitals. Furthermore, unlike other seismic retrofit methods, the seismic isolation retrofit work can be executed without changing neither the design nor space of a building, and the installation of isolators can be made without resettlement of the occupants. Thus, the seismic isolation became a very popular earthquake-resistant technique for seismic retrofitting of existing buildings. The advantages of this technique were shown by experimental work $[17,18]$ and by their successful response during earthquakes [19-21]. Several numerical and experimental studies definitely demonstrated the applicability and potentials of base isolation for the seismic retrofit of buildings not designed to withstand seismic action $[22,23]$. More importantly, there are many examples of application of seismic isolation for the retrofit of existing buildings throughout the world. However, there are relatively few papers available in the literature where the torsional response of base-isolated buildings was studied. The evaluation of the torsional effects can be particularly important in case of multiple buildings on a common isolation basement with the isolation system below [24]. This situation occurs in long base-isolated buildings in which the superstructure consists of several buildings separated by thermal expansion joints and all isolation bearings supporting adjacent buildings are connected together at their top, forming a common isolation system. In this case, the torsional characteristics of the combined system may result in a significant increase of the inelastic deformations of the corner bearings and in an out-of-phase motion with possible impact of adjacent parts of the superstructure. Often the isolation system is designed by simply ignoring torsion in the superstructure or perhaps by considering it only as a secondary effect. Only in recent years, a series of new studies were carried out on multistorey building models. Tena-Colunga and Zambrana-Rojas [25] showed that a greater eccentricity of the base isolation system has an even more negative base displacements effect than the superstructure eccentricity. In [26], it is pointed out that higher torsional amplifications can be expected in the case of a mass eccentric structure than in the case of stiffness eccentric structures. Kilar and Koren [5] studied the behavior of base-isolated asymmetric structures with different plan distribution of the isolators. Seguin et al. [27] developed a systematic method for the optimal torsional control. Wolff et al. [28] showed that the measured torsional amplification ratios correspond to accidental eccentricities of about half of the code-described value of 5 percent of largest plan dimension.

This paper deals with the retrofitting by base isolation of an existing building belonging to the Hospital Center of Avellino (Italy). The building was composed of three reinforced concrete structures that are linked functionally but structurally separated to avoid pounding. The conventional strengthening methods used for seismic retrofitting generally include addition of shear walls and proving adequate seismic gaps between structures. In this way, the three structures would be stiffened and well separated, to avoid pounding during strong earthquakes. As an alternative, in the case study, the three structures were unstiffened using base isolation and joined together at the ground floor. After retrofit, the three existing structures become a single multiple building structure, thus dealing with specific issues concerning design, construction, accidental torsional, and poundings effects.

\section{Original Fixed-Base Structures}

2.1. General Description. The case study is a 5-storey hospital building of the new hospital campus of Avellino in Campania (Italy). The construction of the building was never completed, and only the reinforced concrete skeleton structures were erected (Figure 1). The building was designed after the IrpinoLucano earthquake of 1980 according to the provisions of the Italian Seismic Code of 1986 [29]. The site belongs to the II seismic category zone, whose coefficient of seismic intensity is $C=0.07$. The importance factor $I=1.40$ was considered to increase the seismic design forces for critical structures based on the structural occupancy category. The response spectrum method of seismic analysis was applied for prediction of forces in structural members. The allowable stress design 


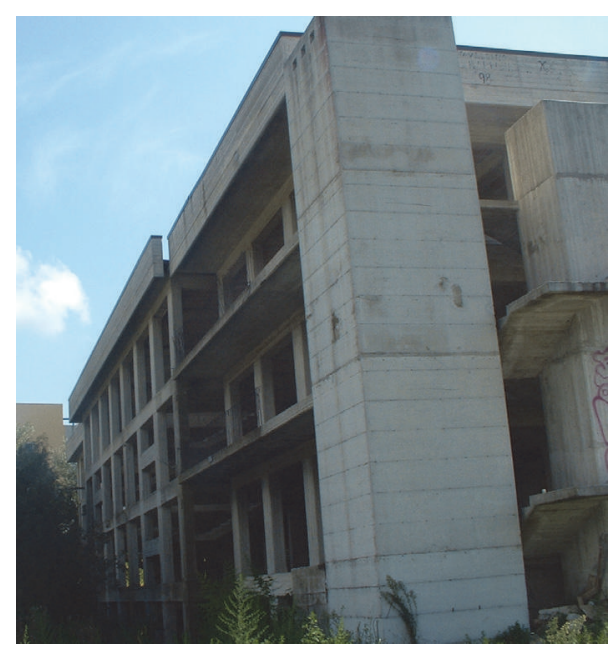

FIGURE 1: View of the original fixed-base building.

method (also called working stress design method) was used in design. In the meantime, the design acceleration given by the last Italian Code [1] for the construction site has been significantly increased. Thus, the seismic resistance of these structures has been found to be well below current standards. The original fixed-base (FB) five-storey building is presented in Figure 2. The building was composed of three reinforced concrete frame structures (named A, B, and C). The required separations between these adjacent structures were created to avoid pounding during earthquakes. The cross sections of the structural members are reported below (Figure 2): Structure A: beams $35 \times 60 \mathrm{~cm}$, first-floor columns $50 \times 70 \mathrm{~cm}$, and other columns $35 \times 70 \mathrm{~cm}$; Structure B and Structure C: first-floor beams $45 \times 60 \mathrm{~cm}$, other beams $35 \times 60 \mathrm{~cm}$, and columns $35 \times 70 \mathrm{~cm}$. All the beams of foundation have the same T-shaped cross section with the following geometry: height $=130 \mathrm{~cm}$, flange thickness $=40 \mathrm{~cm}$, flange width $=$ $145 \mathrm{~cm}$, and web thickness $=110 \mathrm{~cm}$ in dilatation joint and $60 \mathrm{~cm}$ otherwise. The floors have a mixed structure made up of reinforced concrete and brick. Their thickness is $21 \mathrm{~cm}$. The reinforced concrete retaining walls are disconnected from both structures in elevation and foundations.

2.2. In Situ Measurements and Laboratory Tests. The input data were collected from a variety of sources, including available documentation and in situ and laboratory measurements and tests. In particular, the following investigations were carried out: (1) geometrical measurements; (2) soil investigations including sampling and testing; (3) determination of mechanical properties of materials by testing of samples taken from the structure. The soil comprises deposits of heterogeneous clasts in clay matrix of yellowish green colour. The mechanical properties of soil and the ground type according to soil classification of Eurocode 8 [2] were derived from the following geological and geotechnical tests: (1) N.6 soil profile test, N.5 Standard Penetration Tests (SPT), and N.1 Down-Hole Test. The synthesis of results from Down-Hole Test gives the following values of the propagation velocity of $S$-waves: $V_{S}=149 \mathrm{~m} / \mathrm{s}$ in the first $4.5 \mathrm{~m}$ of the soil profile;
$V_{S}=474 \mathrm{~m} / \mathrm{s}$ in the subsequent $30 \mathrm{~m}$. These results give promise that soils can be classified as follows: ground type B $\left(360<V_{S, 30}<800\right.$, where $V_{S, 30}$ is the average value of propagation velocity of $S$ waves in the upper $30 \mathrm{~m}$ of the soil profile at shear strain). The building is situated on a flat ground (topographic amplification factor $S_{T}=1.00$ ). In assessing the earthquake resistance of the existing structures, the last Italian Code [1] was applied. For the purpose of choosing the admissible type of analysis and the appropriate confidence factor $(\mathrm{CF})$, the following three knowledge levels are defined in this Code: KL1: limited knowledge; KL2: normal knowledge; KL3: full knowledge. In the case study, the level of knowledge attained is KL3 (full knowledge). The geometry was known from original outline construction drawings with sample visual survey. The structural details were known from original detailed construction drawings with limited in situ inspection. The information on the mechanical properties of the construction materials was known from original test reports and limited in situ testing. According to the Italian Code [1], the limited programme of in situ testing requires at least one steel material sample per floor for each type of member (beam, column, and wall). Moreover, the Italian Code also recommends one concrete material sample per floor for every $300 \mathrm{~m}^{2}$ of building's total floor area. Therefore, according to the dimensions in plan of the building, at least N.3 concrete material samples per floor for each type of member were required. Some destructive tests (no more than 50\%) were replaced with a larger amount (at least three times) of nondestructive ultrasonic testing. The numbers of specimens were selected considering a single building, since the floors of the three structures were built simultaneously. In the same way, the mean values of the compressive strength of concrete and the tensile strength of steel were calculated using all the values from the in situ testing. In any case, the programme of in situ testing was organized in order to have at least N.1 concrete material sample per floor for each structure $(\mathrm{A}, \mathrm{B}$, and $\mathrm{C})$ and type of member. The testing campaign included: (1) N.12 monotonic compressive tests on cylindrical specimens; (2) N.18 tensile tests on steel rebar; (3) N.46 ultrasonic tests combined with Schmidt rebound hammer tests; (4) radiographic tests. Based on the results of monotonic compressive tests, the following values of the compressive strength of concrete $\left(f_{c}\right)$ were calculated: mean value $f_{c m}=39.86 \mathrm{MPa}$; minimum value $=$ $33.32 \mathrm{MPa}$; maximum value $=50.58 \mathrm{MPa}$; standard deviation $=4.967 \mathrm{MPa}$; coefficient of variation $=0.1246$. The mean value from the combined Sonreb method was 38.45 MPa. Based on the results of tensile tests on steel rebar, the following values of the tensile strength of steel rebar $\left(f_{y}\right)$ were obtained: mean value $f_{y m}=563 \mathrm{MPa}$; minimum value $=484.07$; maximum value $=559.61$; standard deviation $=23.22$; coefficient of variation $=0.0441$. According to Italian Standard [1] and Eurocode 8 [2], the concrete compressive strength and tensile strength of steel rebar were obtained as mean values from in situ tests, appropriately divided by the confidence factors $\mathrm{CF}$, accounting for the level of knowledge attained. In the case study, the level of knowledge attained is KL3 (full knowledge). Thus, the correspondent confidence factors is $\mathrm{CF}=1.00$. 

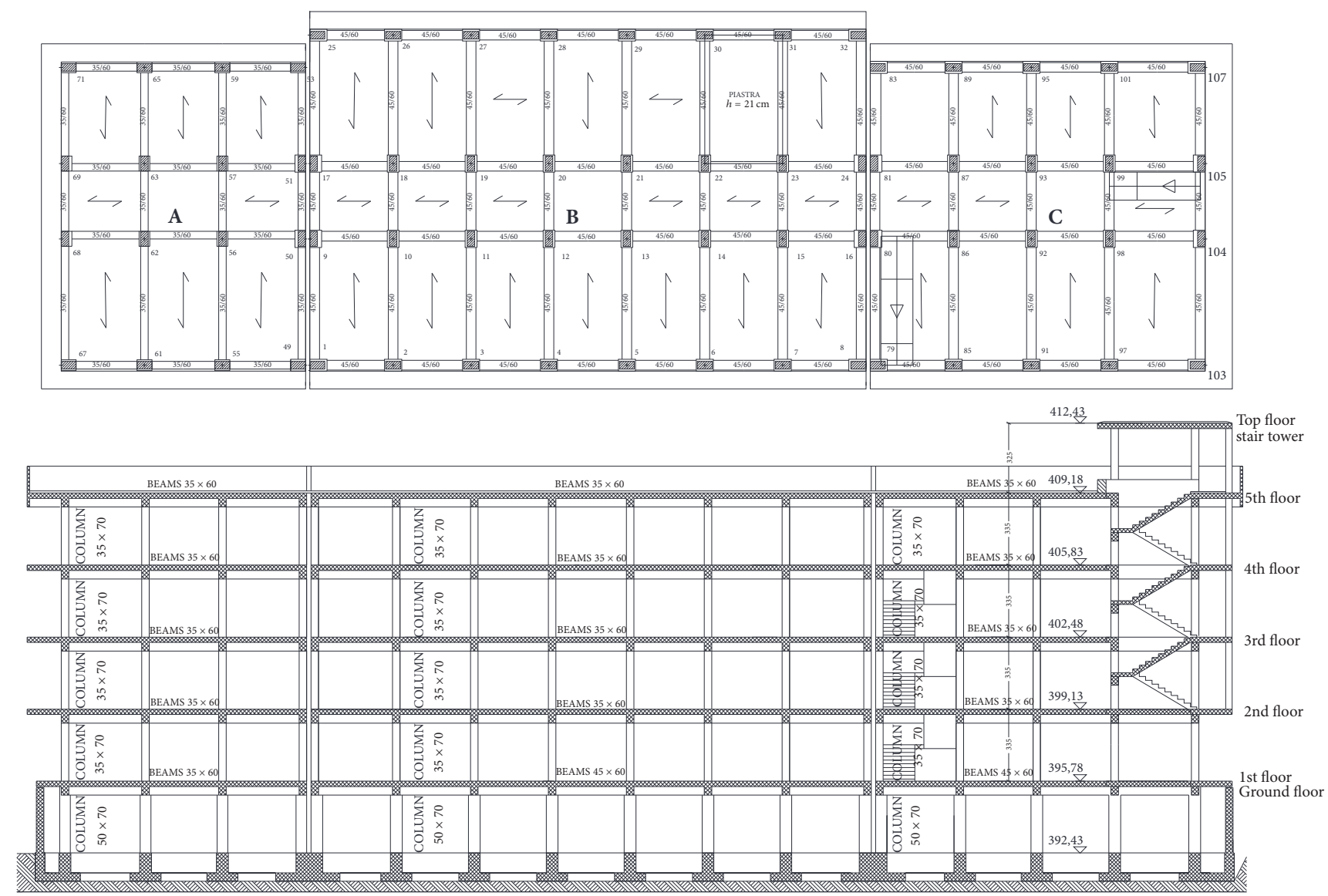

FIgUre 2: Plan and section view of the original building.

2.3. Seismic Assessment. The seismic performance evaluation was carried out with the procedure reported in Annex B of EN 1998-3 [2] and in Italian Code [1]. The seismic safety verification was carried out implementing refined models of the three reinforced concrete structures in a finite element computer program [30]. The design gravity loads were used in the seismic assessment. The permanent gravity loads are (a) $4.00 \mathrm{kN} / \mathrm{m}^{2}$ for the top floor and $5.80 \mathrm{kN} / \mathrm{m}^{2}$ for the other floors. The values of the live loads are $0.50 \mathrm{kN} / \mathrm{m}^{2}$ for the top floor and $3.00 \mathrm{kN} / \mathrm{m}^{2}$ for the other floors. Using the appropriate coefficients from Eurocode 8 [2], the vertical loads were combined with seismic actions in a combination of $1.0 \mathrm{G}+0.15 \mathrm{Q}$ for all the storeys except the top floor, where it was taken equal to $1.0 \mathrm{G}+0.30 \mathrm{Q}$. Four performance levels were considered in the analysis: Table 1 shows the parameters of the elastic design response spectra according to the Italian Code [1]. The Limit State (LS) of Damage Limitation (DL) was defined by the chord rotation at yielding, evaluated by the formula (A.10b) from EN 1998-3 [2] as follows:

$$
\theta_{y}=\phi_{y} \frac{L_{V}}{3}+0.0013\left(1+1.5 \frac{h}{L_{V}}\right)+0.13 \phi_{y} \frac{d_{b} f_{y}}{\sqrt{f_{c}}},
$$

where $\phi_{y}$ is the yield curvature of the end section; $f_{y}$ and $f_{c}$ are the steel yield stress and the concrete strength, respectively, both in $\mathrm{MPa} ; d_{b}$ is the (mean) diameter of
TABLE 1: Parameters of elastic design response spectra [1].

\begin{tabular}{lcccc}
\hline Limit State & IO & DL & LS & CP \\
\hline Probability of exceedance $P_{V R}$ & 0.81 & 0.63 & 0.10 & 0.05 \\
Return Period $T_{R}$ (years) & 120 & 201 & 1898 & 2475 \\
Peak ground acceleration PGA/g & 0.109 & 0.139 & 0.318 & 0.345 \\
Amplification factor $F_{0}$ & 2.346 & 2.350 & 2.470 & 2.489 \\
Transition Period $T_{C}(\mathrm{~s})$ & 0.336 & 0.350 & 0.398 & 0.406 \\
\hline
\end{tabular}

the tension reinforcement. The Limit State of DL was also defined by drift acceptance criteria related to the performance level. According to the Damage Limitation requirement of Eurocode 8 [2], the drift ratio was limited to 0.005 for buildings having nonstructural elements of brittle materials attached to the structure. In the same way, the Limit State of Immediate Occupancy (IO) was defined by a drift that is assumed as $2 / 3$ of the drift ratio for the LS of DL. The Limit States of Life Safety (LS) and Collapse Prevention (CP) were verified by comparison between the structural capacity and the seismic demand. To this aim, a nonlinear model based on concentrated plasticity was implemented in a finite element computer program [30]. The plastic hinge model is based on the $3 \mathrm{D}$ interaction surface which defines coupling between axial (P) and biaxial-bending (M2-M3) 
behaviors (PMM hinge model). Plastic hinge generalised load against deformation diagrams used for the modelling was considered bilinear. The elastic stiffness of the bilinear forcedeformation relation was equal to the secant stiffness corresponding to the initiation of yielding of the reinforcement. The stress-strain model originally proposed by Mander et al. [31] was used for confined concrete. Confinement factors were estimated according to Eurocode 8 [2] and varied along the member length according to the arrangement of the transverse reinforcements. The steel was modelled with an elastic-plastic-hardening relationship. The rigid elements were placed at beam-column connections to prevent the development of plastic hinges inside the connections. The capacity of ductile and brittle members was estimated in terms of chord rotation and shear strength, respectively. The deformation capacity of beams and columns was defined in terms of the chord rotation. The value of the chord rotation capacity of beam-column members for the Limit State (LS) of Collapse Prevention (CP) was evaluated by the formula A.1 from EN 1998-3 [2] as follows:

$$
\begin{gathered}
\theta_{u}=\frac{1}{\gamma_{\mathrm{el}}} 0.016 \cdot\left(0.3^{\nu}\right)\left[\frac{\max \left(0.01 ; \omega^{\prime}\right)}{\max (0.01 ; \omega)} f_{c}\right]^{0.225} \\
\cdot\left(\frac{L_{V}}{h}\right)^{0.35} 25^{\left(\alpha \rho_{s x}\left(f_{y w} / f_{c}\right)\right)} \cdot\left(1.25^{100 \rho_{d}}\right),
\end{gathered}
$$

where $\theta_{u}$ is the total chord rotation capacity; $\gamma_{\mathrm{el}}$ is equal to 1.5 for primary seismic elements and 1.0 for secondary seismic elements; $h$ is the depth of cross section; $L_{V}=M / V$ is the ratio moment/shear at the end section; $v=N /\left(b h f_{c}\right)$ is the normalized axial force $(b=$ width of compression zone; $N$ = axial force positive for compression); $\omega$ and $\omega^{\prime}$ are the mechanical reinforcement ratio for the tension and compression, respectively; $f_{c}$ and $f_{y w}$ are the concrete compressive strength $(\mathrm{MPa})$ and the steel yield strength $(\mathrm{MPa})$, respectively, directly obtained as mean values from in situ tests, appropriately divided by the confidence factors, accounting for the level of knowledge attained; $\rho_{s x}=$ $A_{s x} /\left(b_{w} s_{h}\right)$ is ratio of transverse steel parallel to direction $x$ of loading ( $s_{h}=$ stirrup spacing); $\rho_{d}$ is the steel ratio of diagonal reinforcement in each diagonal direction; $\alpha$ is the confinement effectiveness factor evaluated by formula A.2 from EN 1998-3 [2]. The chord rotation relative to the Limit State (LS) of Life Safety (LS) was assumed as 3/4 of the ultimate chord rotation. The capacity curve, which represents the relation between base shear force and control node displacement, was determined with the nonlinear static (pushover) analysis in accordance with Italian Code [1] and Eurocode 8 [2]. The transformation to an equivalent Single Degree of Freedom (SDOF) system reported in the Annex B of EN 1998-3 [2] allows plotting the structural capacity (pushover) curve in the ADRS (Acceleration-Displacement Response Spectrum) format. The capacity acceleration spectra of the three existing structures are detailed in Figures 3-5. According to the Italian Code [1], the pushover analysis was carried out in two directions ( $X$ and $Y$ ). The load vectors were obtained as a product of the floor masses and two chosen profiles of horizontal accelerations: (1) First Mode: acceleration profile corresponding to the fundamental mode; (2) Uniform (rectangular): constant horizontal accelerations along the height of the structure. The worldwide assumed code value of $\pm 5 \%$ was considered for accidental eccentricity. Figures 3-5 show that a large plastic deformation capacity is obtained in most of the cases examined since the collapse occurs by a global plastic mechanism. In some cases, a local failure mechanism activates, resulting due to formation of plastic hinges in first-storey columns prior to those in beams. This situation typically occurs in the case of building structures $\mathrm{A}$ and $\mathrm{C}$ under the uniform distribution of the lateral loads. The transformation to an equivalent Single Degree of Freedom (SDOF) system allows plotting both capacity and demand in spectral-acceleration versus spectral-displacement coordinates. The target displacement $d_{t}{ }^{*}$ was calculated using the procedure originally proposed by Fajfar [32] and then implemented in Annex B of EC8 [2] and Italian Code [1]. This procedure is equivalent to the capacity spectrum method based on inelastic demand spectra [33], if the reduction rule proposed by Vidic et al. [34] to obtain the Inelastic Demand Response Spectrum (IDRS) from the Elastic Demand Response Spectrum (EDRS) is applied. This allows comparing capacity and demand in the spectral plane and calculating the target displacement $d_{t}{ }^{*}$ for the equivalent SDOF system and the corresponding peak ground acceleration (PGA), according to Annex B of EN 1998-3 [2]. Summarized in Table 1 are the values of the target displacement $\left(d_{t}{ }^{*}\right)$ and peak ground acceleration (PGA) for the Limit States (LS) of Immediate Occupancy, Life Safety, and Collapse Prevention. These values represent the capacity of the existing building structures to resist seismic actions in terms of peak ground acceleration (PGA) on type A ground corresponding to the Limit States of the structure $\left(\mathrm{PGA}_{\mathrm{IO}}^{c}\right.$; $\left.\mathrm{PGA}_{\mathrm{DL}}^{c} ; \mathrm{PGA}_{\mathrm{LS}}^{c}\right)$. Thus, these values may be compared with the reference peak ground accelerations on type $A$ ground for the construction site. Shown in Table 2 are the values of PGA corresponding to a return period of 120 years $\left(\mathrm{PGA}_{\mathrm{IO}}^{d}\right.$, IO Limit State), 201 years ( $\mathrm{PGA}_{\mathrm{DL}}^{d}$, DL Limit State), 1898 years $\left(\mathrm{PGA}_{\mathrm{LS}}^{d}\right.$, LS Limit State), and 2475 years $\left(\mathrm{PGA}_{\mathrm{CP}}^{d}, \mathrm{CP}\right.$ Limit State). Figure 6 compares demand and capacity in terms of PGA. The points on the left of the bisector correspond to analyses for which verification is not satisfied (demand > capacity). The points on the right of the bisector correspond to analyses for which verification is satisfied (demand < capacity). The preliminary seismic assessment reveals that the existing structures generally satisfy the verification of the Damage Limitation Limit State (DL) and almost verify the immediate occupancy requirements. On the contrary, an unsatisfactory seismic behavior was found for the LS and CO prevention Limit States, especially for the structures A and $\mathrm{C}$ depending on their insufficient lateral capacity and limited ductility. More details about the activities carried out to assess the seismic performance of the existing structures are extensively described in Ferraioli et al. [35, 36].

\section{Seismic Retrofit with Base Isolation}

3.1. Seismic Design. The retrofitting of existing buildings may be carried out with two alternative strategies, taking into 


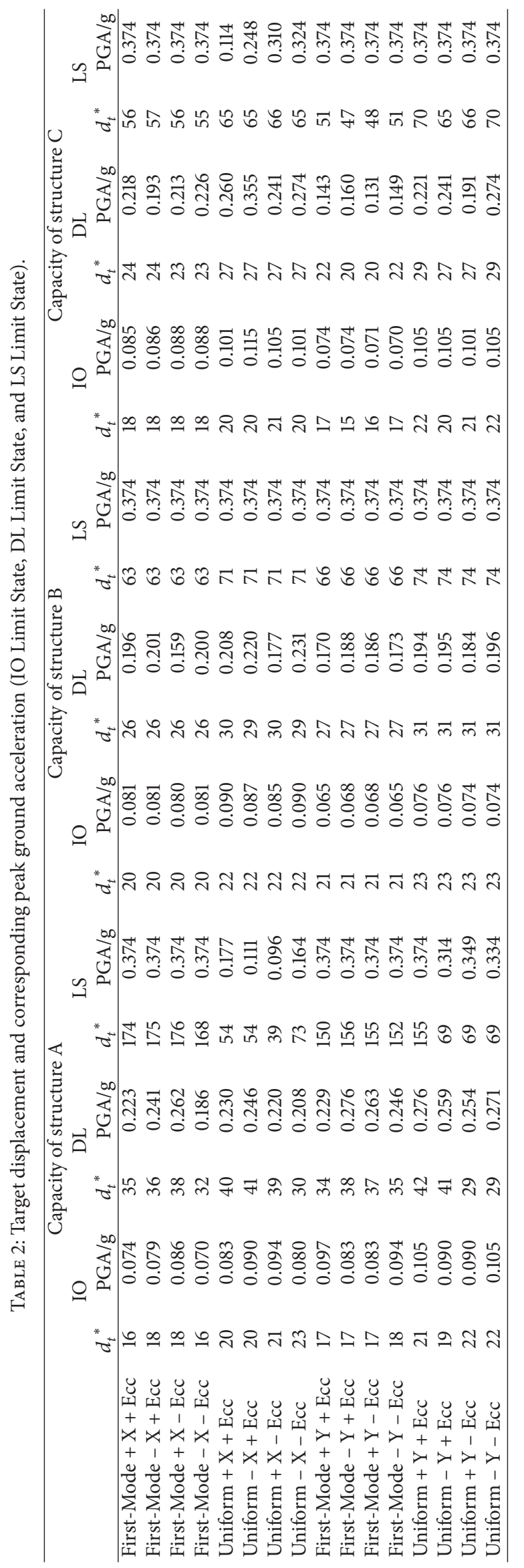




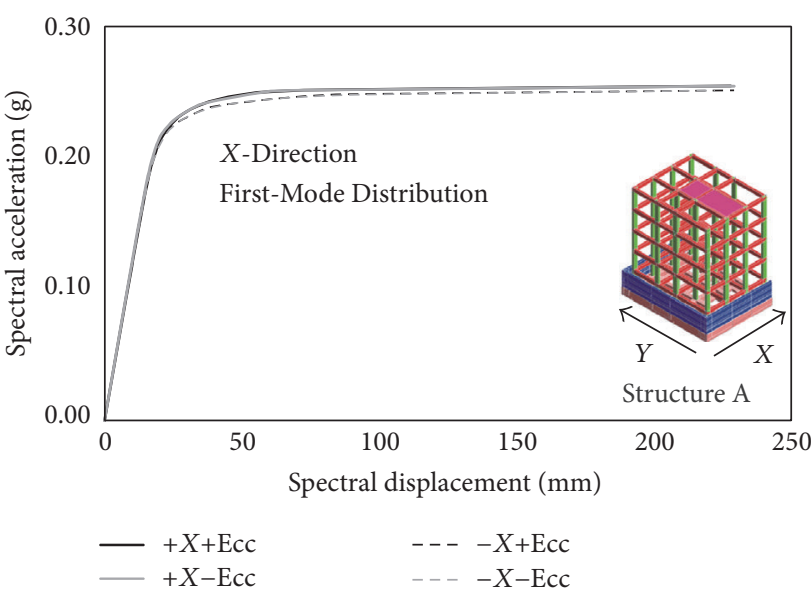

(a)

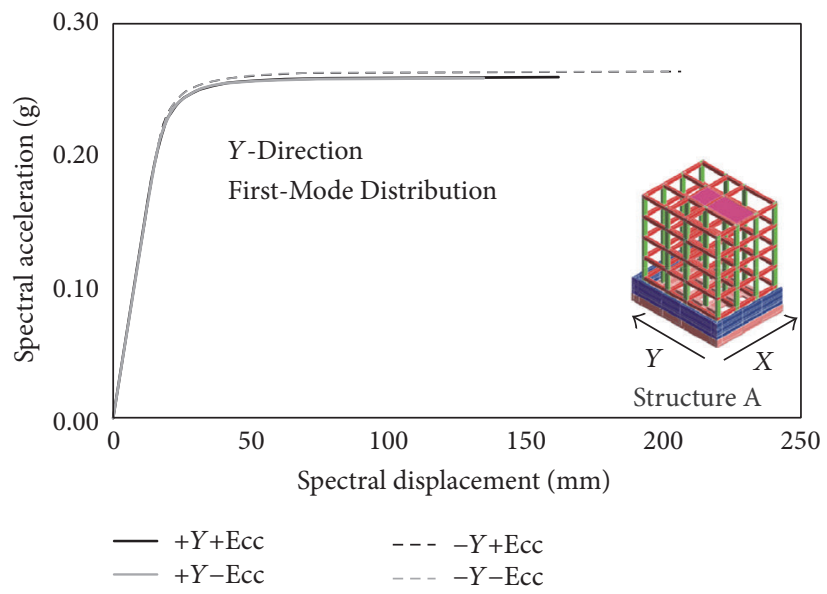

(c)

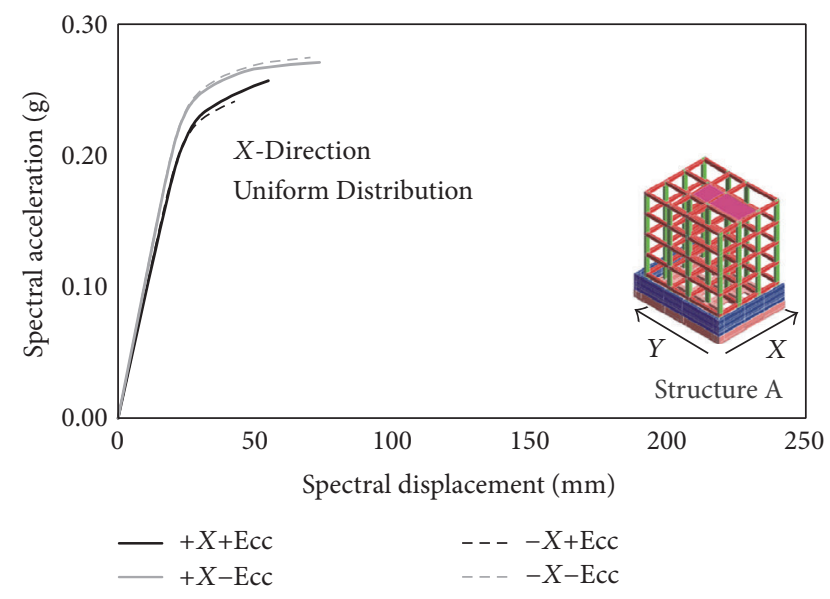

(b)

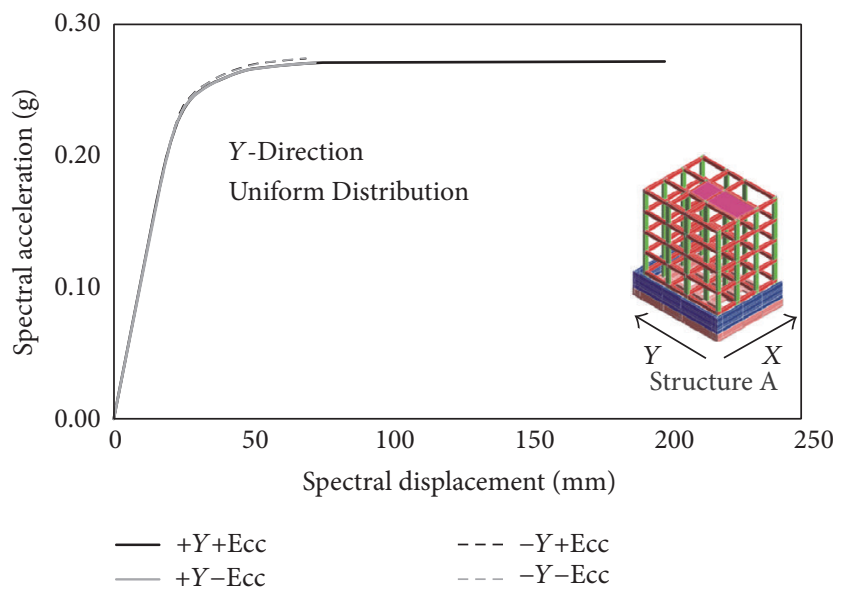

(d)

Figure 3: Capacity acceleration spectra of structure A (accidental eccentricity $\pm 5 \%$ ). (a) $X$-Direction First-Mode Distribution. (b) $X$ Direction Uniform Distribution. (c) Y-Direction First-Mode Distribution. (d) Y-Direction Uniform Distribution.

account the two aspects of seismic design: demand and capacity. The first one is based on conventional retrofitting methods and include addition of new structural elements (shear wall and bracings) to the system, enlarging the existing members (column and beam jacketing, thickening existing walls), strengthening with steel plate or carbon fiber sheet. These methods increase the capacity of the structure (strength and/or stiffness) to meet the likely demand. However, these conventional strengthening methods usually increase the acceleration of the buildings by increasing their stiffness. Moreover, these conventional strengthening methods involve extensive modifications of the building at all levels and the loss of its functionality. The second strategy for the retrofitting of existing buildings is based on seismic isolation and energy dissipation techniques that are methods of reducing the demands on the structure so that its existing capacity is sufficient to withstand the design earthquake. Thus, most construction work is confined at the level of isolation and the functionality of the building is maintained. Seismic isolation bearings fall into two main categories: elastomeric bearings and sliding bearings. There are two commonly used types of sliding bearings: flat sliding bearings, which are generally used in combination with elastomeric systems, and friction-pendulum (FPS) type bearings. The frictional pendulum system, originally proposed by Zayas et al. [7], is a sliding seismic isolation system which uses its surface curvature to generate the restoring force from the pendulum action of the weight of the structure. The FPS bearings present some advantages: high rigidity to wind and minor earthquake loads; high vertical load capacity and stability; high dissipation and recentreing capacity, longevity, and durability characteristics. Moreover, the natural period of the isolated structure is independent by the mass of the superstructure, as it only depends on the radius of the sliding surface. This is a very important property because it makes the behavior of FPS bearings nominally independent of axial loads. On the contrary, to maintain stability of the elastomeric bearings under large lateral displacements, their diameters become large. The increase in bearing diameter results in stiffer bearings, making isolation of light structures difficult.

In the case study, the application of traditional methods of seismic retrofitting based on stiffness and strength increase would raise problems of convergence. In fact, the period shortening of the structure increases the seismic demand. 

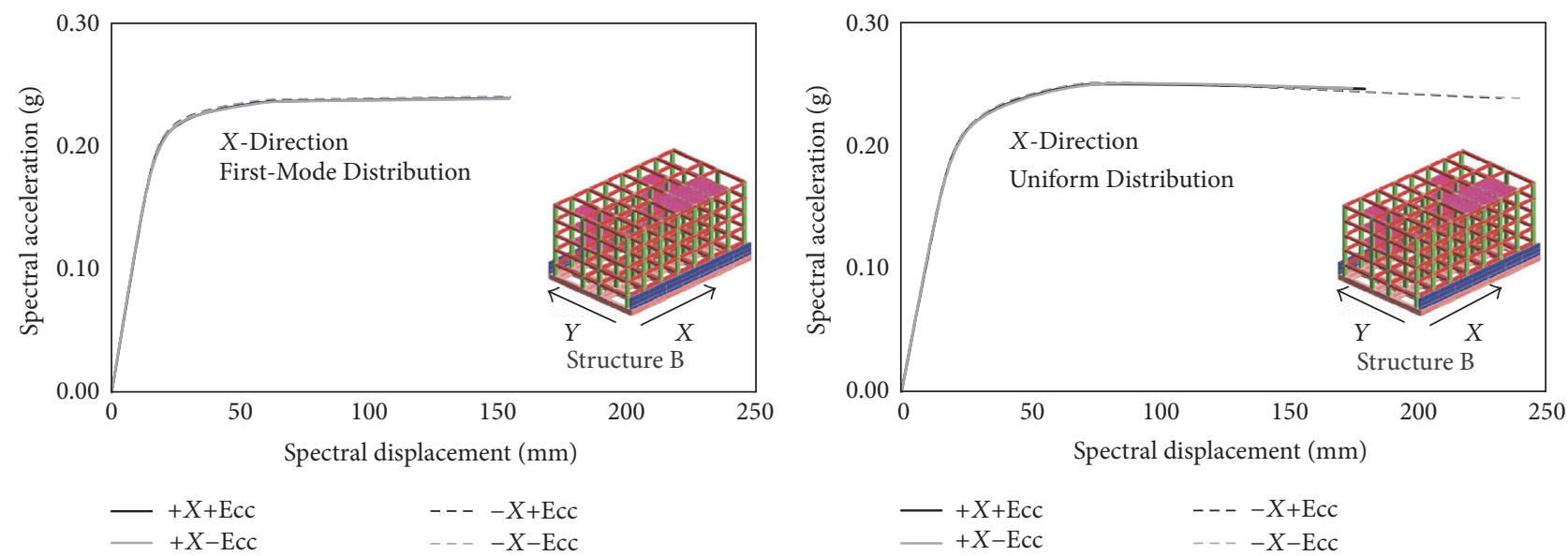

(a)

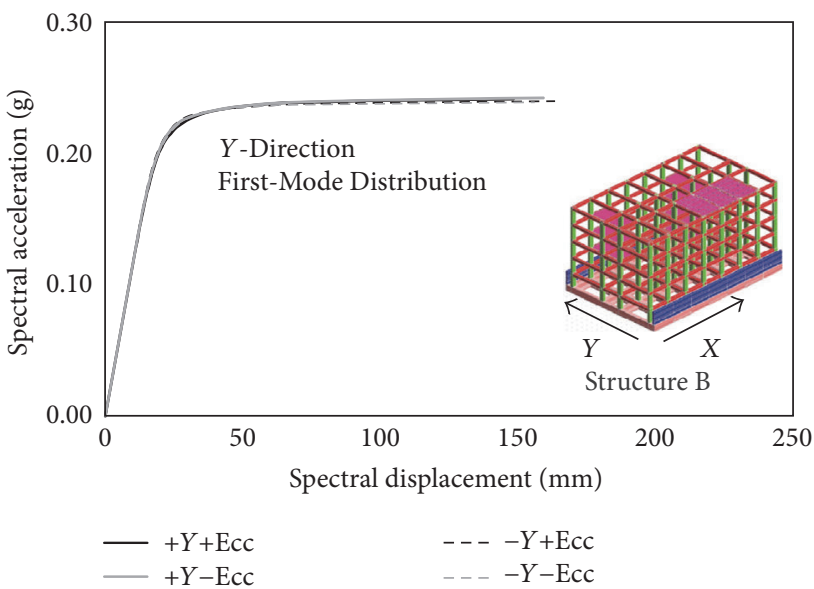

(c)

(b)

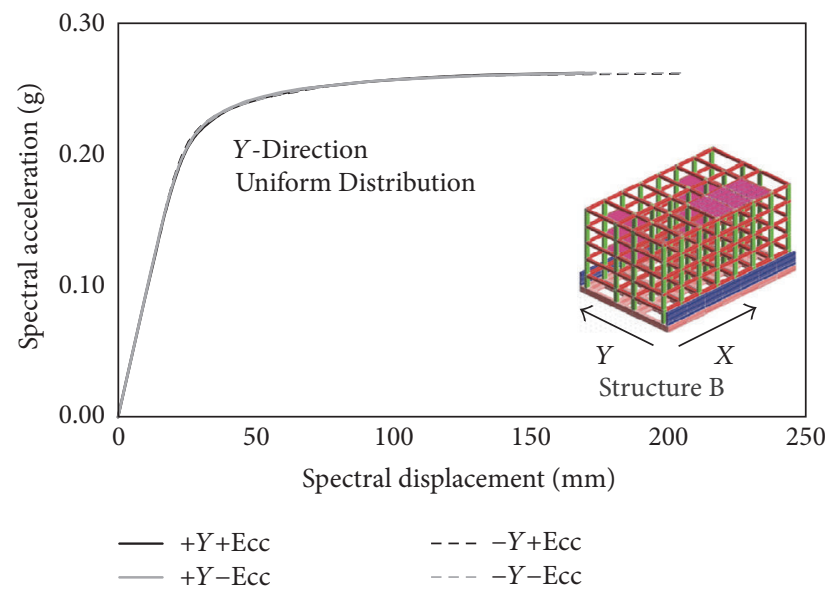

(d)

FIgURE 4: Capacity acceleration spectra of structure B (accidental eccentricity $\pm 5 \%$ ). (a) $X$-Direction First-Mode Distribution. (b) $X$ Direction Uniform Distribution. (c) Y-Direction First-Mode Distribution. (d) Y-Direction Uniform Distribution.

Thus, the capacity increase would be partly alleviated by the increase in seismic demand, and extensive strengthening interventions on structural members would be required to solve the balance between seismic demand and structure capacity. As an alternative, the retrofitting of the existing structures was based on seismic isolation. The seismic retrofit design was carried out by eliminating the seismic separation gap at ground level, thus creating a common isolation plane. To this aim, beam to beam, column to column, and slab to slab connections were realized across the separations gaps. The floor slab was strengthened by increasing its depth from top and adding $12 \times 12$ steel rebar wire mesh anchored in the slabs. The isolation bearings were installed after cutting the bottom portion of the columns under the ground floor. Thus, the three existing reinforced concrete structures were transformed in a base-isolated multiple building structure (Figures 7 and 8). The isolation system is composed of 25 circular shaped High Damping Rubber Bearings (HDRBs) with three diameters, namely, 600, 650, and $800 \mathrm{~mm}$. Some plane surfaces steel-teflon (PTFE) Sliding Devices (SDs) were coupled to HDRBs. Figure 9 shows the plan layout of the isolation system. The base isolation system is composed of different rubber bearings. The reason is that the diameter must increase with the vertical load to maintain the stability of the bearing under large lateral displacements. The increase in bearing diameter resulted in stiffer bearings, making it necessary to use flat sliding bearings in combination with the rubber bearings. The plan layout of HDRBs and SDs was selected in such a way as to minimize the torsion effects due to any eccentricity between the centre of mass of the superstructure and the centre of rigidity of the isolation system. However, since the slenderness ratio $\lambda=L_{\max } / L_{\min }$ (height to base ratio) of the building in plan is 3.26 , the accidental torsional effects may be anyhow significant. A seismic gap was provided around a seismically isolated building to facilitate the large relative displacements at the isolation level. The stairs and elevators crossing the isolation level are usually a key problem in the retrofitting of existing buildings. The main connections between the building and the ground (such as stairs, entryways, elevators, and pipes) need to be unconnected across the isolation plane or designed to accommodate the displacement of the isolation system. In the case study, the internal stairs and elevators do not cross the isolation interface. The external stairways and access 


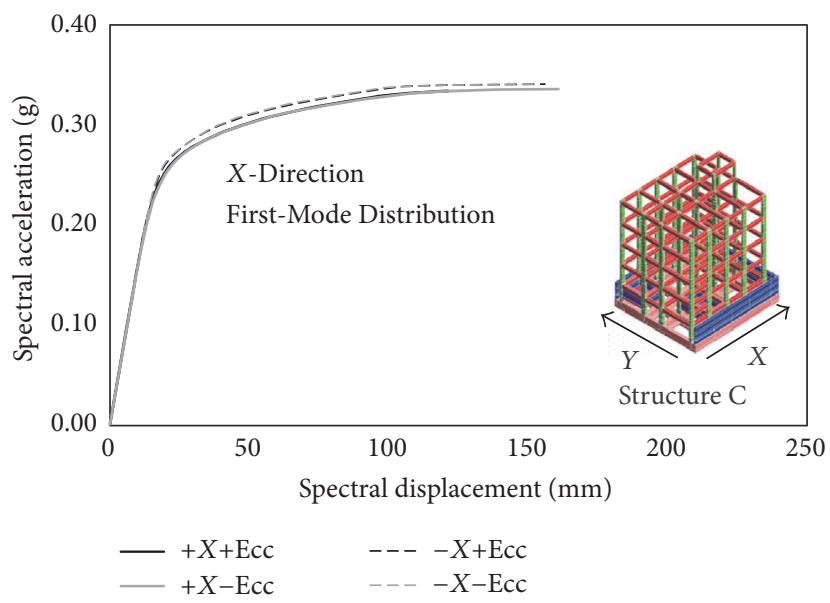

(a)

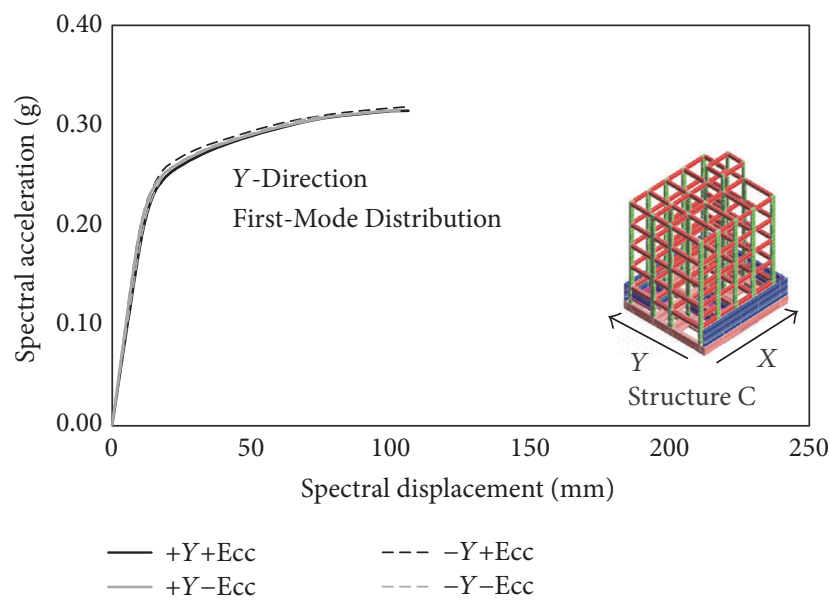

(c)

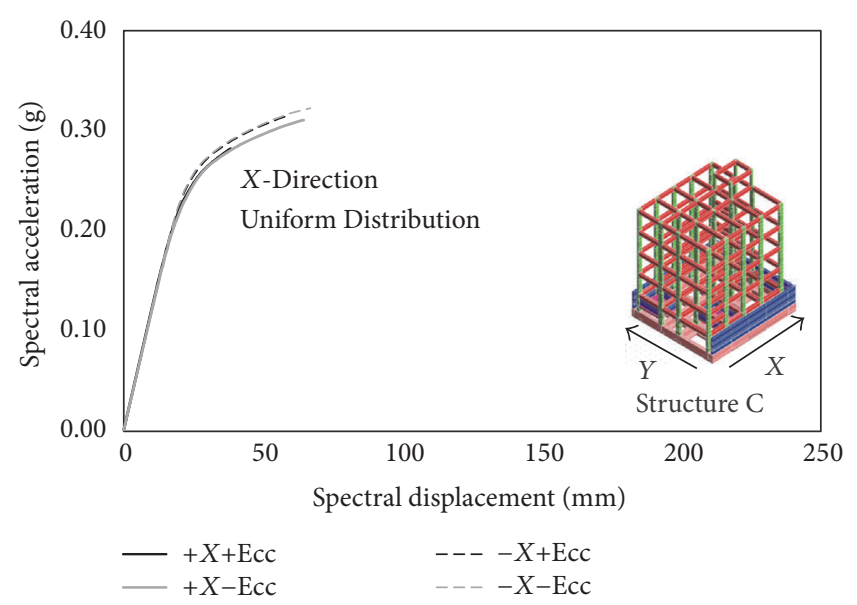

(b)

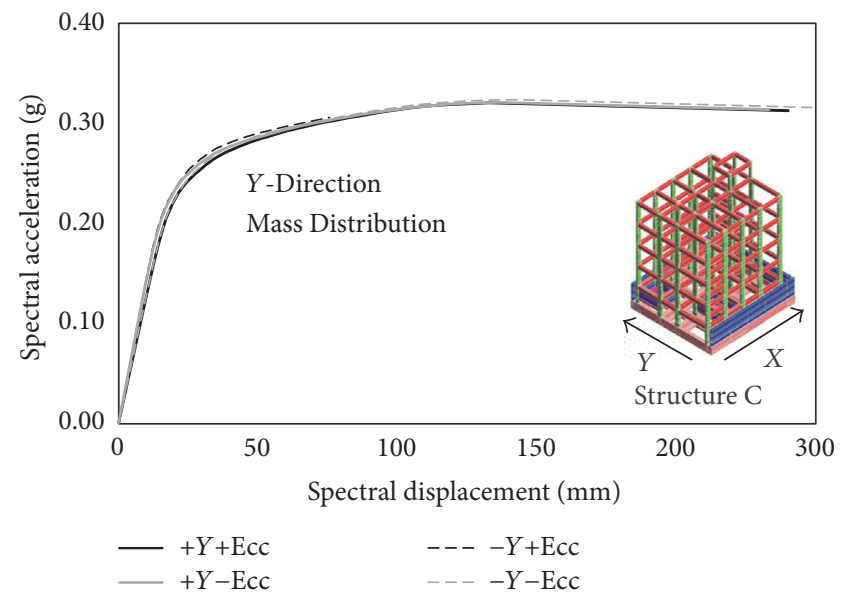

(d)

Figure 5: Capacity acceleration spectra of structure C (accidental eccentricity $\pm 5 \%$ ). (a) $X$-Direction First-Mode Distribution. (b) $X$ Direction Uniform Distribution. (c) Y-Direction First-Mode Distribution. (d) Y-Direction Uniform Distribution.

points were detailed to be fixed to the superstructure and be "simply supported" on the structure below the isolators. Utilities and pipes that cross the seismic plane were detailed to move horizontally.

The design of the base-isolated structure was based on the Italian Seismic Code [1]. The isolation bearings were manufactured by FIP Group (Padova, Italy). The elastomeric isolators are reinforced rubber bearings belonging to the series SI (FIP SI-S 600/180, FIP SI-S 650/180 and FIP SI$S$ 800/180). The design displacement was $d_{d c}=350 \mathrm{~mm}$. The free Sliding Devices are pot-type bearings from Vasoflon series FIP (VM 200/700/700, VM 350/700/700 and $2 \times$ VM 200/700/700 for coupled columns). The mechanical properties of the isolation rubber bearings used for the sample structure are summarized in Table 3. Qualifying and acceptance testing was carried out on a sample of HDRBs following the protocol required by the Italian Seismic Code [1]. Table 4 shows the results of the acceptance tests carried out on the rubber bearings. In Figure 10, the shear versus transverse displacement relationship of the SI-S 800/180 rubber bearing under a sinusoidal displacement history is plotted. It is noted that the HDRBs exhibit stable energy dissipation capacity at large shear deformations under cyclic loads. The forcedeformation relationship of the rubber bearings may be defined assuming an equivalent linear viscoelastic model. In fact, the limitations prescribed by the Italian Seismic Code [1] and Eurocode [2] are met. Specifically, (a) the effective stiffness of the isolation system is at least $50 \%$ of the effective stiffness at $20 \%$ of design displacement $d_{d c}$; (b) the effective damping ratio of the isolation system does not exceed $30 \%$; (c) the force-displacement characteristics of the isolation system do not vary by more than $10 \%$ due to the rate of loading or due to the vertical loads; (d) the increase of the restoring force in the isolating system for displacement between $0,5 d_{d c}$ and $d_{d c}$ is at least $2,5 \%$ of the total gravity load above the isolating system. The response spectrum method of seismic analysis was applied for prediction of forces in structural members. The ultimate Limit State design method was used to calculate the strength of the structure. The structural model of the isolated structure is reported in Figure 11. The floor diaphragms were considered as being rigid in their planes since they have sufficient in-plane stiffness. This hypothesis was justified according to the Italian Code [1] and Eurocode 8 [2] provisions. To 

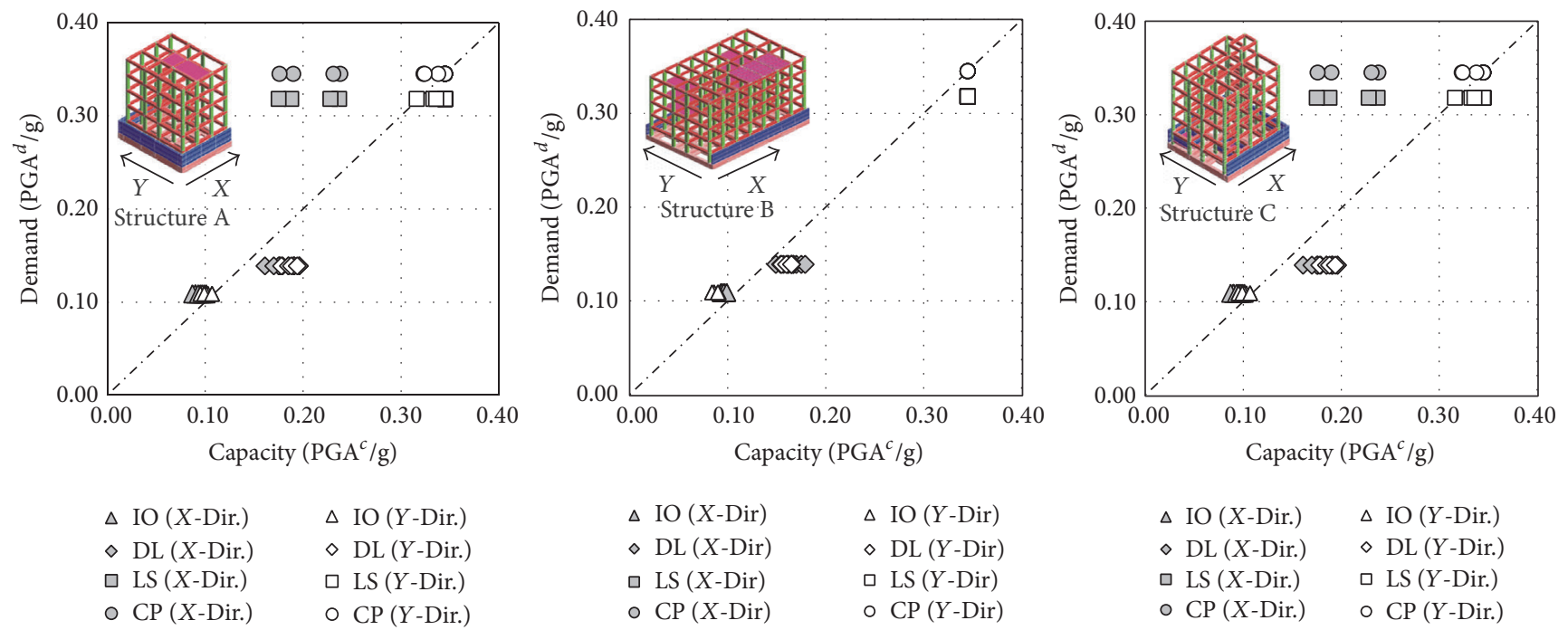
$\Delta \mathrm{IO}(X-\mathrm{Dir})$
$\Delta \mathrm{IO}(Y$-Dir $)$
$\diamond \mathrm{DL}(X-\mathrm{Dir})$
$\diamond \mathrm{DL}(Y$-Dir $)$
ㄴS (X-Dir)
$\square$ LS (Y-Dir)
- $\mathrm{CP}(X-\mathrm{Dir})$
- $\mathrm{CP}(Y$-Dir $)$

\begin{abstract}
$\Delta \mathrm{IO}(X$-Dir. $) \quad \Delta \mathrm{IO}(Y$-Dir. $)$
$\diamond \mathrm{DL}(X$-Dir. $) \diamond \mathrm{DL}(Y$-Dir. $)$

$\square$ LS (X-Dir.) $\square$ LS (Y-Dir.)

- $\mathrm{CP}(X$-Dir.) $\quad$ ○ $\mathrm{CP}(Y$-Dir. $)$
\end{abstract}

FIGURE 6: Peak ground acceleration on type A ground corresponding to demand ( $y$-axis) and capacity ( $x$-axis).

TABLE 3: Nominal properties of rubber bearings.

\begin{tabular}{|c|c|c|c|c|c|c|c|c|c|c|c|c|}
\hline Isolator Type & $V[\mathrm{kN}]$ & $F_{z d}[\mathrm{kN}]$ & $K_{e}[\mathrm{kN} / \mathrm{mm}]$ & $K_{v}[\mathrm{kN} / \mathrm{mm}]$ & $D_{g}[\mathrm{~mm}]$ & $t_{e}[\mathrm{~mm}]$ & $h[\mathrm{~mm}]$ & $H[\mathrm{~mm}]$ & $Z[\mathrm{~mm}]$ & $W[\mathrm{~kg}]$ & $S_{1}$ & $S_{2}$ \\
\hline SI-S 600/168 & 1010 & 5410 & 0.67 & 813 & 600 & 168 & 268 & 318 & 850 & 435 & 18.1 & 3.45 \\
\hline SI-S 650/180 & 1260 & 6260 & 0.74 & 854 & 650 & 180 & 277 & 327 & 700 & 507 & 17.5 & 3.50 \\
\hline SI-S 800/180 & 3400 & 13280 & 1.12 & 1506 & 800 & 180 & 281 & 341 & 850 & 835 & 19.5 & 4.33 \\
\hline
\end{tabular}

$V=$ maximum vertical seismic load; $F_{z d}=$ maximum vertical design load in Ultimate Limit State (ULS); $K_{e}=$ effective lateral stiffness; $K_{v}=$ vertical stiffness; $D_{g}=$ diameter; $t_{e}=$ total rubber thickness; $h=$ total height (not including anchor plates); $H=$ total height (including anchor plates); $Z=$ side length of anchor plates; $W$ = weight without anchor bolts; $S_{1}=$ primary shape factor; $S_{2}=$ secondary shape factor.

TABLE 4: Acceptance tests results on rubber bearings.

\begin{tabular}{ccccc}
\hline$N$. & Isolator Type & $\begin{array}{c}\text { Vertical stiffness } \\
K_{v}[\mathrm{kN} / \mathrm{mm}]\end{array}$ & $\begin{array}{c}\text { Dynamic shear modulus } \\
G_{\text {din }}[\mathrm{MPa}]\end{array}$ & $\begin{array}{c}\text { Static shear modulus } \\
G_{\text {stat }}[\mathrm{MPa}]\end{array}$ \\
$\begin{array}{c}\text { damping } \\
\xi[\%]\end{array}$ \\
\hline 1 & SI-S 800/180 & 1508 & 0.30 & 0.46 \\
2 & SI-S 800/180 & 1524 & 0.31 & 0.46 \\
3 & SI-S 800/180 & 1501 & 0.31 & 0.46 \\
4 & SI-S 800/180 & 1512 & 0.30 & 0.46 \\
5 & SI-S 650/180 & 862 & 0.33 & 0.45 \\
6 & SI-S 650/180 & 828 & 0.30 & 16.2 \\
\hline
\end{tabular}

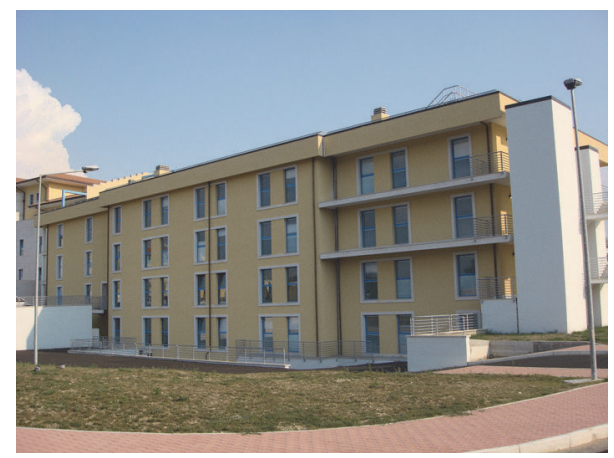

FIGURE 7: View of the hospital building after retrofit.

this aim, two analyses were carried out, one neglecting and the other considering the diaphragm in-plane flexibility. The diaphragm is considered as rigid because the diaphragm flexibility nowhere increases the horizontal displacements by more than $10 \%$. The high stiffness and strength of the foundation allowed the foundation-structure interaction to be neglected. Table 5 gives the dynamic properties of the isolated structure (modal period, spectral acceleration at various Limit States, and modal mass ratios $\alpha_{x}$ and $\alpha_{y}$ in $x$ - and $y$-directions). The following damping ratios were considered during linear analysis: $\xi=15 \%$ for the three lower mode shapes that are dominated by the isolation system and $\xi=5 \%$ for the higher mode shapes that are dominated by the superstructure. The value of the damping correction factor $\eta$ was determined by the following expression:

$$
\eta=\sqrt{\frac{10}{(5+\xi)}} \geq 0.55
$$



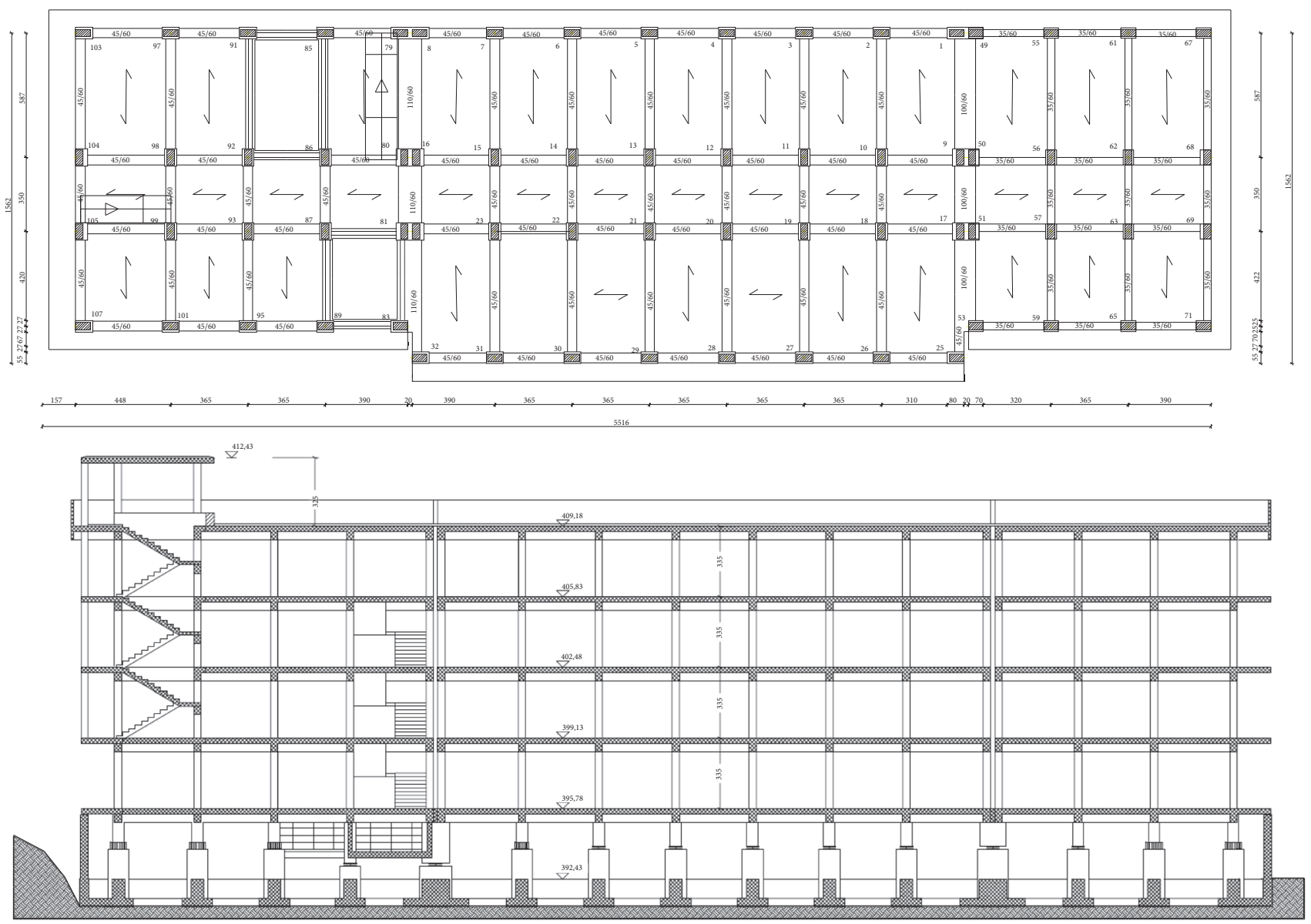

FIGURE 8: Plan and section view of the hospital building after retrofit.

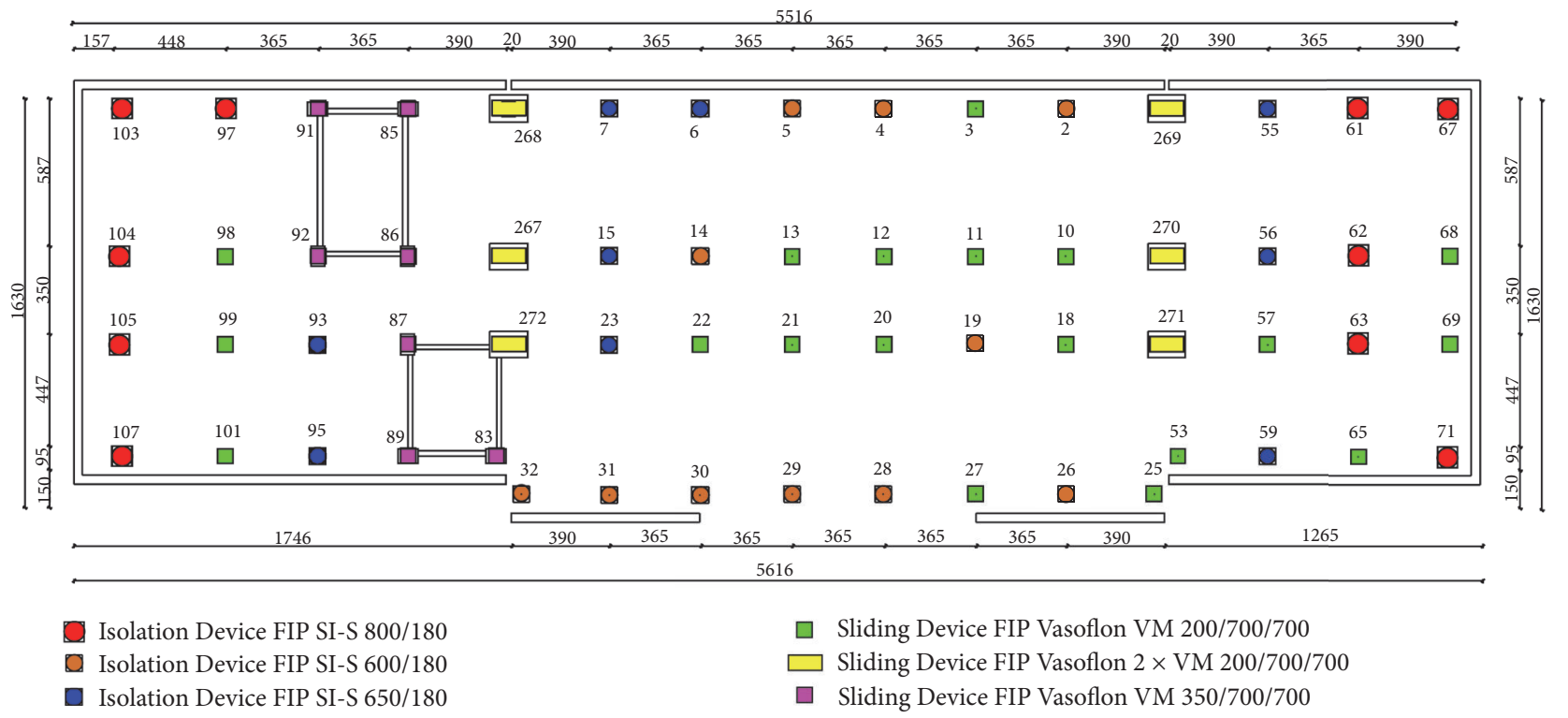

FIGURE 9: Plan layout of the isolation system. 

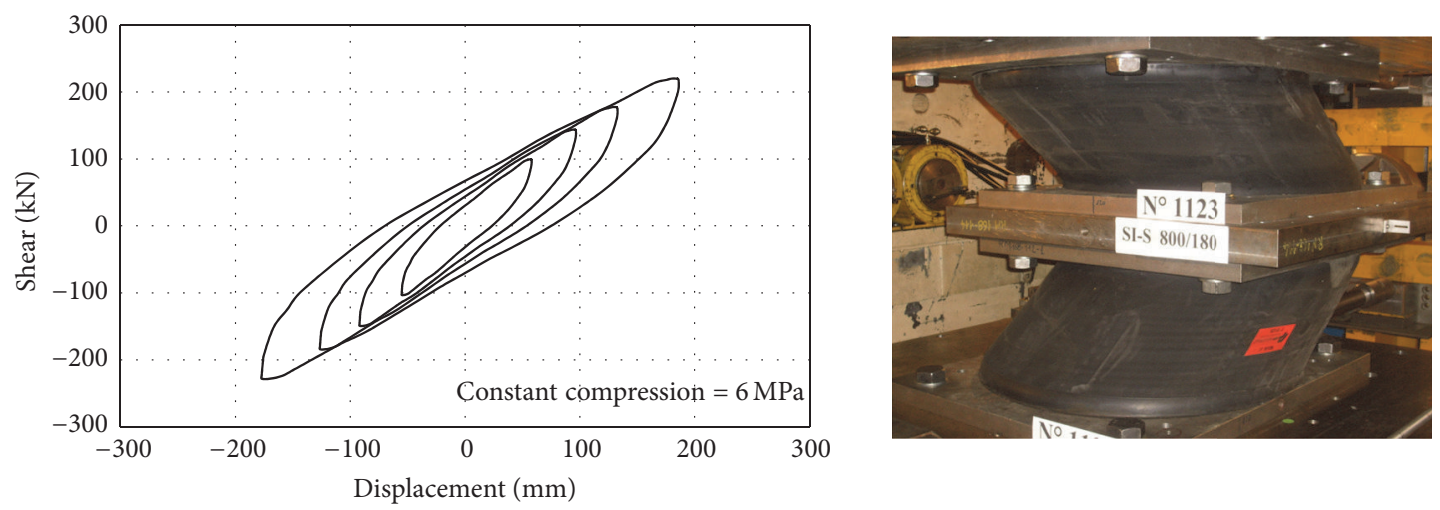

FIGURE 10: Shear versus transverse displacement relationship (Seismic Isolator SI-S 800/180). Sinusoidal displacement history. Results from dynamic test. Loading frequency $=0.5 \mathrm{~Hz}$.

TABLE 5: Dynamic properties of isolated structure.

\begin{tabular}{lcccccccc}
\hline Mode & Period (sec) & $\xi(\%)$ & $\alpha_{x}(\%)$ & $\alpha_{y}(\%)$ & $S_{a} / g(\mathrm{IO})$ & $S_{a} / g(\mathrm{DL})$ & $S_{a} / g(\mathrm{LS})$ & $S_{a} / g(\mathrm{CP})$ \\
\hline 1 & 3.020 & 15 & 0.00 & 99.98 & 0.032 & 0.044 & 0.100 \\
2 & 3.014 & 15 & 99.99 & 0.00 & 0.032 & 0.044 & 0.100 \\
3 & 2.250 & 15 & 0.00 & 0.01 & 0.056 & 0.078 & 0.198 \\
4 & 0.367 & 5 & 0.00 & 0.00 & 0.307 & 0.392 & 0.853 & 0.112 \\
5 & 0.364 & 5 & 0.00 & 0.00 & 0.307 & 0.392 & 0.853 & 0.907 \\
6 & 0.342 & 5 & 0.00 & 0.00 & 0.307 & 0.392 & 0.853 & 0.907 \\
7 & 0.323 & 5 & 0.00 & 0.00 & 0.307 & 0.392 & 0.853 & 0.907 \\
8 & 0.320 & 5 & 0.00 & 0.00 & 0.307 & 0.392 & 0.853 & 0.907 \\
\hline
\end{tabular}

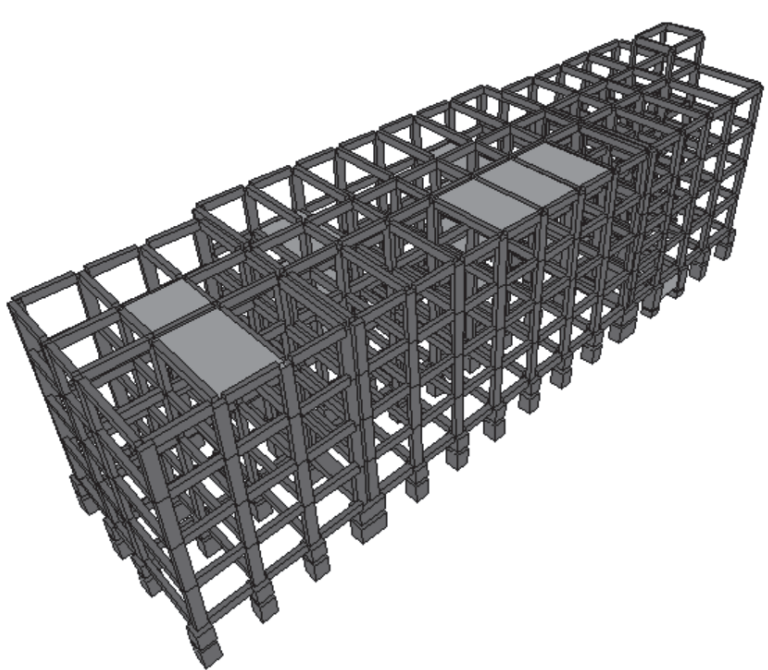

FIGURE 11: Three-dimensional finite element model of base-isolated multiple building structure.

The design spectrum was scaled down through $\eta$-factor. Specifically, $\xi=5 \%$ in the range $T<0.8 T_{\text {ISO }}$, while $\xi=15 \%$ for $T \geq 0.8 T_{\text {ISO }}$, where $T_{\text {ISO }}$ is the fundamental period of the base-isolated structure. In Figure 12, the design acceleration spectra (a) and design displacement spectrum (b) are plotted. In Figure 13, the roof plan of the first eight mode shapes is plotted. It can be observed that the first three mode shapes are dominated by the isolation system, while the other mode shapes are dominated by the superstructure. According to Italian Code [1] and Eurocode 8 [2], the behavior factor is taken as being equal to $q=1.5$ for the design of the superstructure [37], whereas $q=1$ for the design of isolation system, foundation, and substructure, which is the part of the structure located under the isolation interface and anchored to the foundation. The action effects due to the combination of the horizontal components of the seismic action were computed using the $100 / 30$ percentage rule in compliance with the Italian Seismic Code [1]. The analysis of the accidental torsion was carried out considering the methods to be suitably applied in the case of a multiple building structure. The accidental eccentricity accounts for inaccuracies in the distribution of masses in the structure. Design codes usually take it into account as an accidental mass eccentricity that is defined as a fraction of the size of the structure. This accidental eccentricity may be considered either as real mass eccentricity or as additional torsional actions (simplified method according to the design codes). The principle requirement of Eurocode 8 [2] for accidental torsional effects prescribed that the calculated centre of mass at each floor $i$ shall be considered displaced from its nominal location in each direction by an accidental eccentricity:

$$
e_{a i}= \pm 0.05 L_{i}
$$

where $L_{i}$ is the floor dimension perpendicular to the direction of the acting seismic action. On the other side, according 


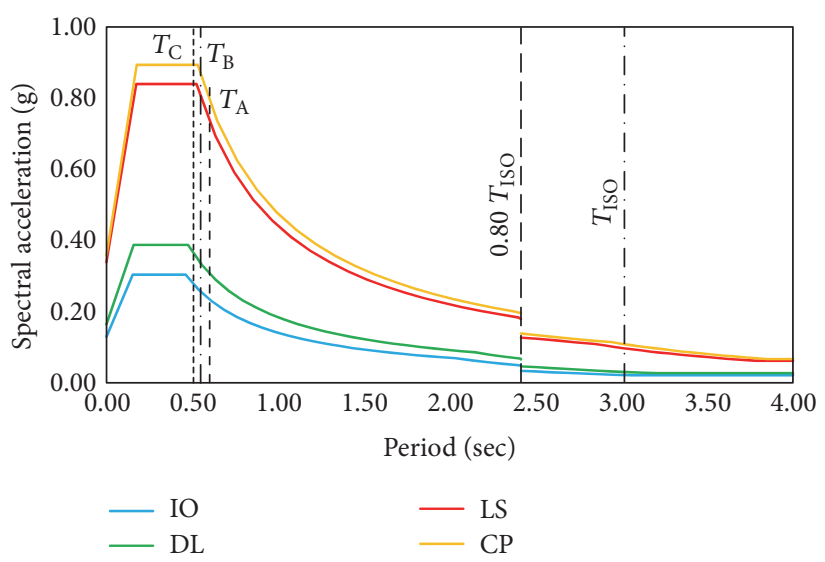

(a)

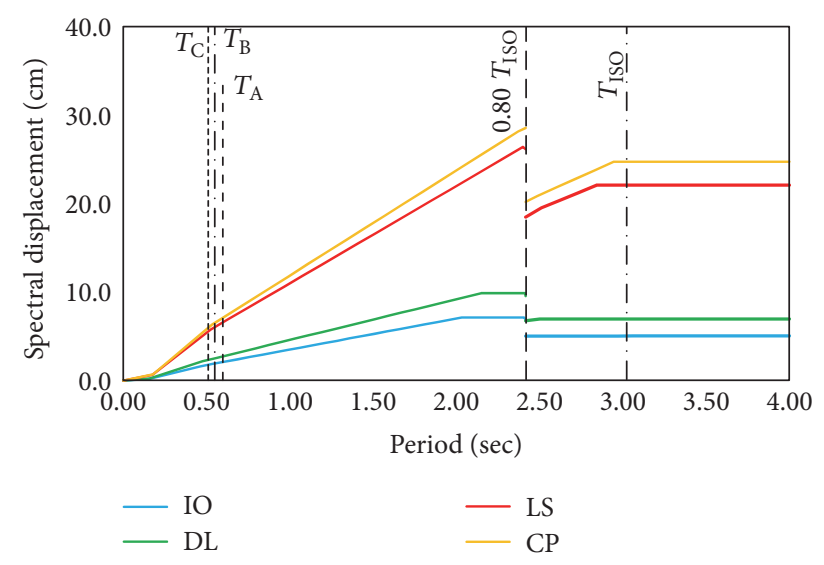

(b)

FIGURE 12: (a) Design acceleration spectra. (b) Design displacement spectrum.

to both Italian Code [1] and Eurocode 8 [2], the accidental torsional effects could be determined as the envelope of the effects resulting from the application of static loadings, consisting of sets of torsional moments $M_{a i}$ about the vertical axis of each storey $i$ :

$$
M_{a i}=e_{a i} \cdot F_{i},
$$

where $M_{a i}$ is the torsional moment applied at storey $i$ about its vertical axis, $e_{a i}$ is the accidental eccentricity of storey mass $i$ for all relevant directions, and $F_{i}$ is the horizontal force acting on storey $i$ as derived from the lateral force method of analysis. In simplified models where the structural eccentricity appears explicitly, it is very simple to add the accidental eccentricity in the calculation. In complex 3D models, the structural eccentricity does not appear as such and it is, therefore, more difficult to account for its effects in such a case. Moreover, it must be observed that both approaches are based on the hypothesis that the floor diaphragms are rigid while, in the case study, the superstructure is composed of three parts disconnected by separation gaps. Thus, the application of these methods for the evaluation of the torsional effects is not possible. In this paper, a 3D model was used for the baseisolated building. In this model, the mass was generated from the load patterns and the accidental eccentricity was taken into account acting to the mass multipliers so to create the required additional torsional actions.

3.2. Installation of Isolation Bearings. The design idea is to supply this building with seismic isolation by gradually cutting it from its foundation and installing the isolators on the top of the first storey of the building rather than the base of the building (midstorey isolation design). This technique is gaining popularity because it enhances the construction feasibility and combines together both aesthetics and functionality. The cutting of the columns was carried out by providing a temporary structure able to transfer the load from the superstructure to the substructure during the introduction of the base isolation bearing into the gap. This structure will then be reused for future interventions of replacement and maintenance of the devices. This aspect suggested to provide an easily transportable provisional metal structure. In Figures 14 and 15, some of the installation phases of the seismic isolation bearings are shown. The general procedure is to transfer the load from the column to two hydraulic jacks, cut the column, place the bearing, and then transfer the load from the jacks to the isolator. The sequence of operations for the installation of each bearing is described as follows:

(1) The basement columns were strengthened with a thick layer of reinforced concrete C28/35 jacketing them below the section that will be occupied by the isolators (Figure 16). The longitudinal and transverse reinforcement were made of steel grade B450C. The anchor bolts were fixed before the concrete casting to attach the bottom steel plate.

(2) Epoxy grouted threaded rods are placed in drilled holes in the column to attach the temporary propping. These anchors will remain in place and can be reused for future interventions of maintenance and/or replacement of the devices.

(3) The temporary propping was located on hydraulic jacks to take the full axial load of the column.

(4) The equipment was attached to measure the load and deformation sustained by temporary supports.

(5) The temporary supports were pushed up using hydraulic jacks so as to transfer the building weight from the column to the temporary supports.

(6) The concrete section of the column was demolished. Two cuts (lower first and then upper) were made through the column with a wire saw. The wire cuts were carried out through the concrete and steel reinforcing of the column. A section of the column was isolated to allow space for the base isolation bearing.

(7) The steel plates for mounting rubber bearings were attached to the top and bottom of the cut column. 


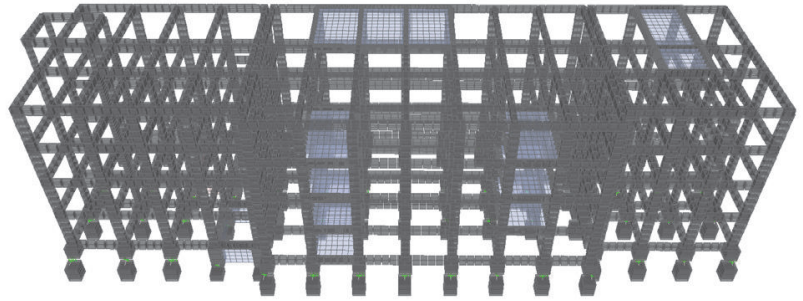

First-Mode shape, $1^{\circ}$ flexural $Y$

Period $3.020 \mathrm{sec}$

Mode shape dominated by isolation system

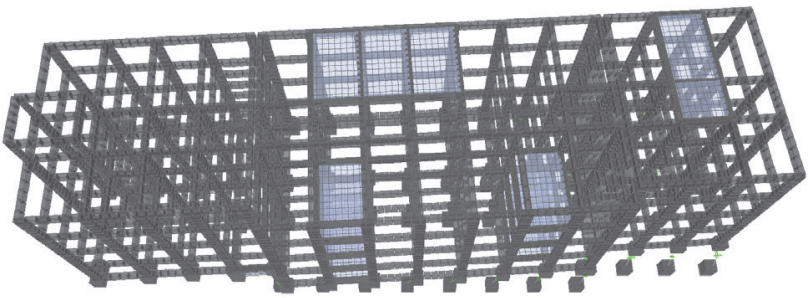

Third-Mode shape, torsional

Period $2.265 \mathrm{sec}$

Mode shape dominated by isolation system

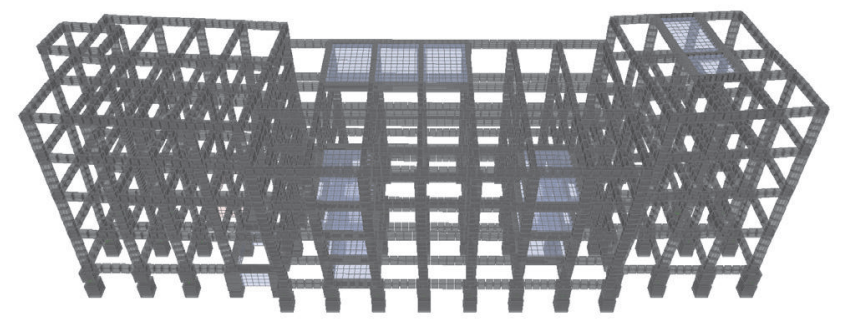

Fifth-Mode shape, flexural $Y$

Period $0.364 \mathrm{sec}$

Mode shape dominated by superstructure

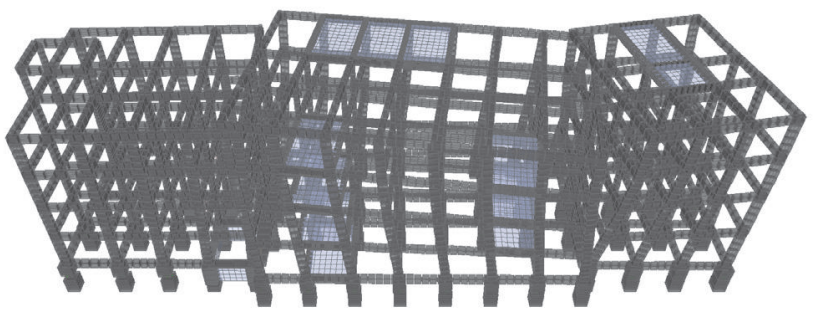

Seventh-Mode shape, torsional Period $0.323 \mathrm{sec}$

Mode shape dominated by superstructure

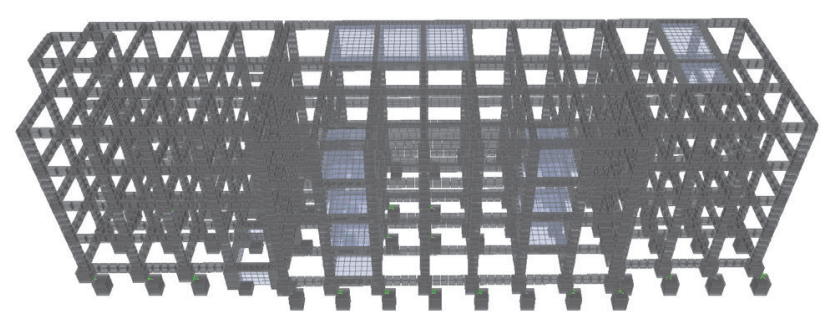

Second-Mode shape, $1^{\circ}$ flexural $X$ Period $3.014 \mathrm{sec}$

Mode shape dominated by isolation system

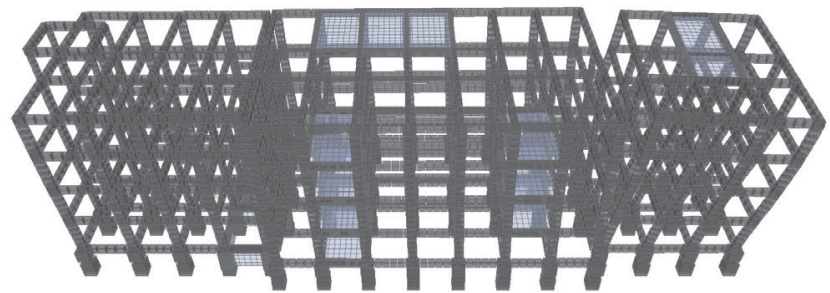

Fourth-Mode shape, flexural $X$ Period $0.367 \mathrm{sec}$

Mode shape dominated by superstructure

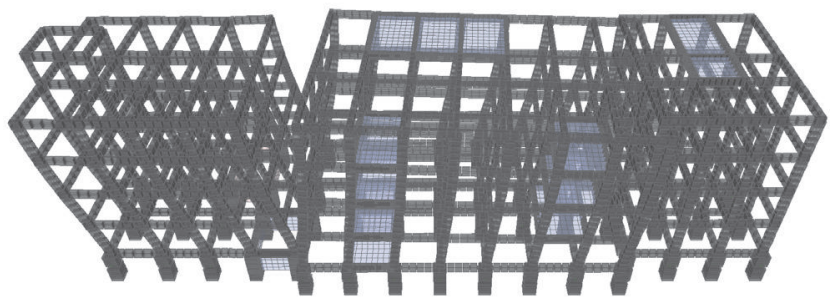

Sixth-Mode shape - flexural $X$ Period $0.342 \mathrm{sec}$ Mode shape dominated by superstructure

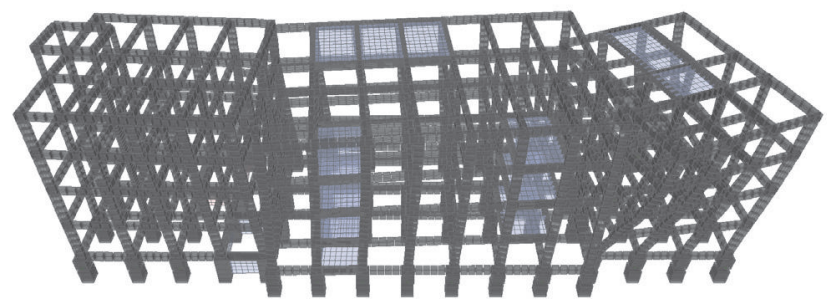

Eighth-Mode shape, torsional Period $0.320 \mathrm{sec}$

Mode shape dominated by superstructure

FIGURE 13: First eight mode shapes.

(8) Where necessary, strengthening steel plates were attached to the section above and below the cut column.

(9) The pre-deformed-and-blocked rubber bearings were mounted between the top and bottom steel plates. The base isolation bearing was introduced into the gap with the use of a trolley. The bearing height and level were adjusted with screw jacks.
(10) The space between the top plate and the upper column section and, similarly, the space between the bottom plate of the bearing and the lower section of the column was filled with cementitious grout.

(11) The hydraulic jacks were destressed in the reverse sequence of loading to allow the column load to be applied to the bearing. The compression in the bearing was taken up by progressive settlement of the whole building. 


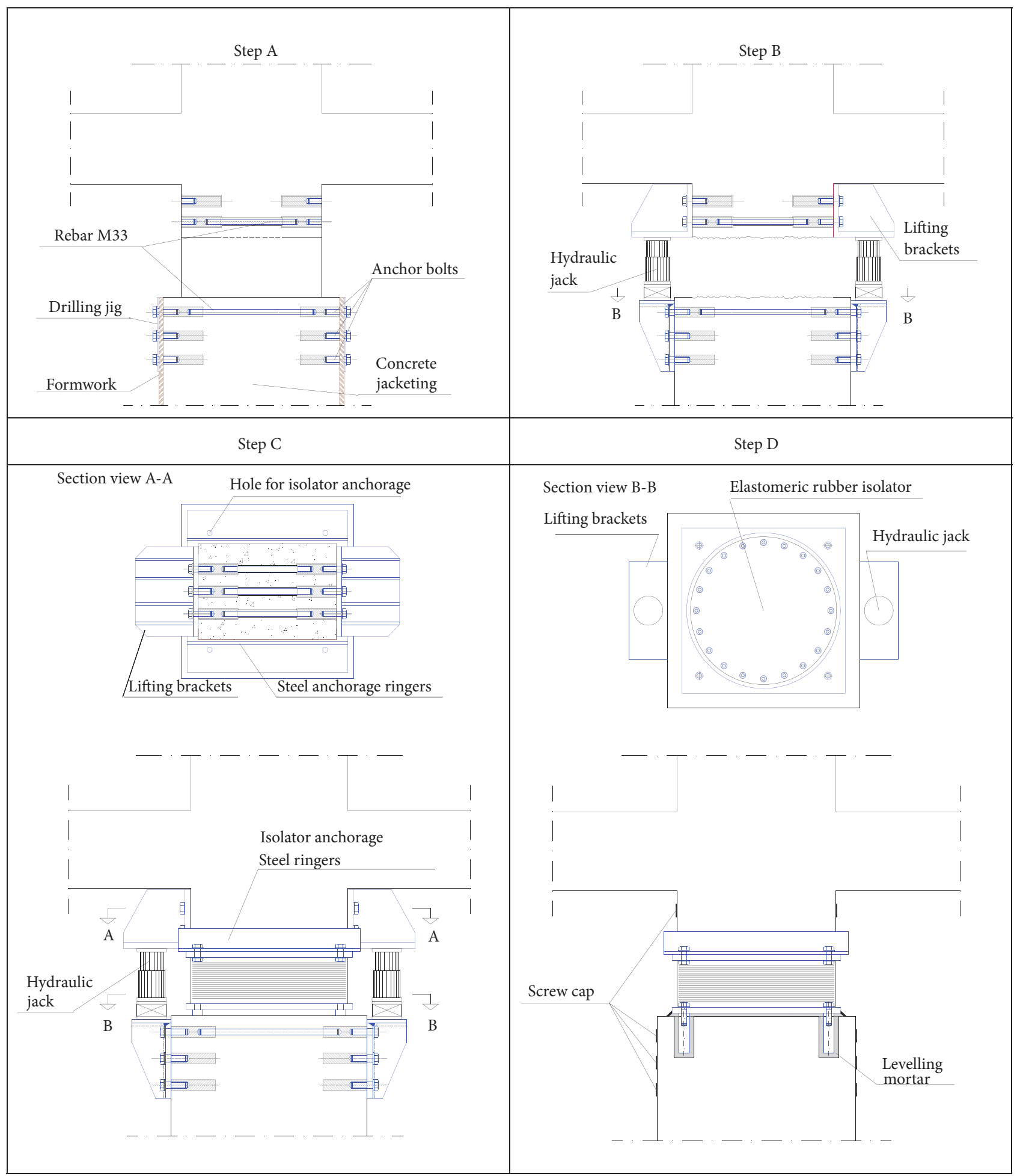

FIGURE 14: Installation phases of reinforced rubber bearings (courtesy of FIP Group).

(12) The temporary supports were removed.

In this project, sensors to monitor the displacements during the cut of the columns were not used. However, the bearing installation was made one column at a time, working from the centre of the building towards each end. No harmful differential settlement or cracking of partitions walls due to movements of surrounding/supporting concrete structures was observed during the installation phases of the isolation bearings. Figures 17 and 18 show the view of the isolation bearings after construction from the underground level and from outside, respectively. Finally, it must be pointed out 


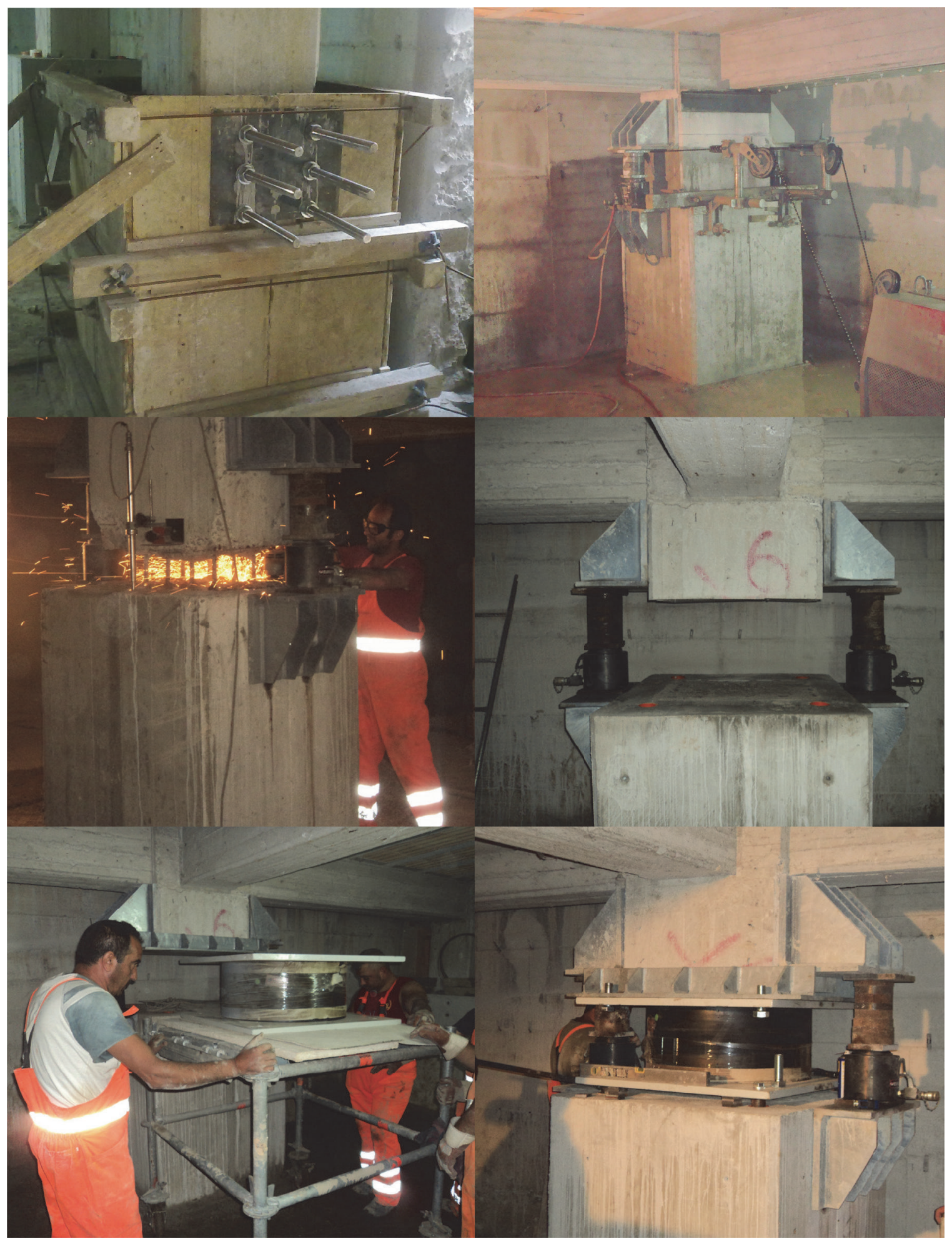

FIGURE 15: Strengthening of the basement columns with a thick layer of reinforced concrete jacketing. Cutting out the concrete section of the column. Transfer of the building weight from the column to the temporary supports. Release of hydraulic jacks and transfer of building load to the rubber bearing. 


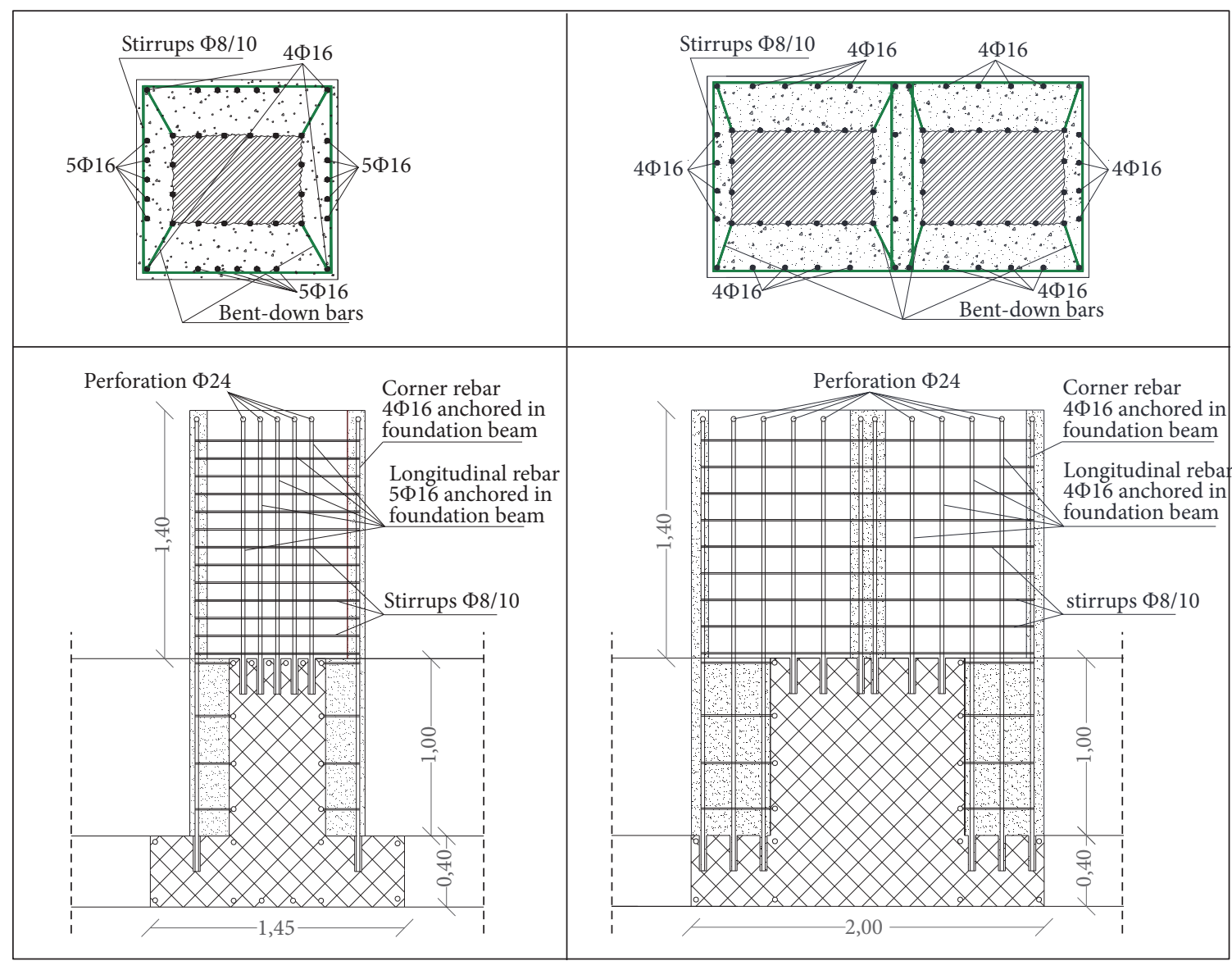

FIGURE 16: Retrofitting of the columns.

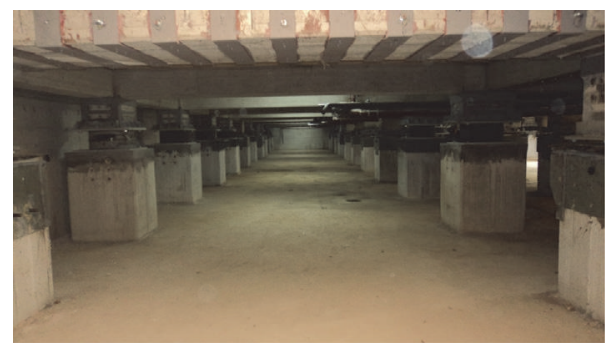

Figure 17: View of isolation bearings from the underground level.

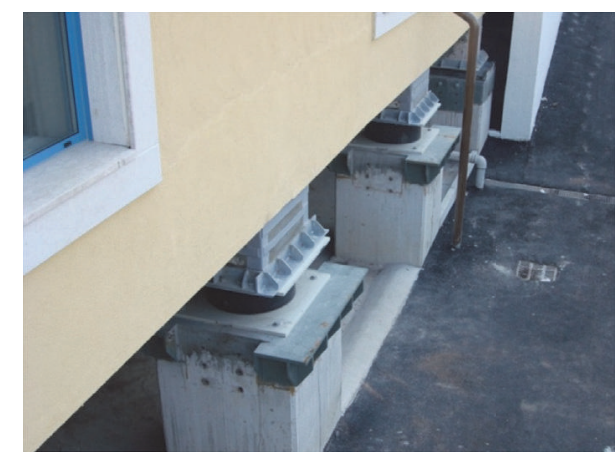

FIGURE 18: View of isolation bearings from outside. that the rubber bearings are formed of thin rubber layers and steel plate chemically bonded together and susceptible to degradation at high temperature. Thus, these bearings are decisive in the structure's fire safety if directly subjected to the exposure of potential fire hazard. This project did not require passive fire protection due to being in a space without a fire load, as is typical in a basement. In cases where the fire protection is required, the most cost-effective method is to use fire-rated board materials over metal framing. However, a fire engineering assessment can rationalize or eliminate the need for fire protection.

\section{Seismic Assessment}

4.1. Nonlinear Dynamic Analysis. The base isolation is a way of mitigating seismic demands in structures. Thus, the superstructure should behave elastically or almost rigidly and the nonlinearity should be confined to the isolators. However, the nonlinear time-history analysis of important base-isolated structures is not uncommon, and often a nonlinear model of the superstructure is considered. Recent seismic codes $[1,2,38-40]$ have specific chapters dedicated to the modelling 
and analysis of base-isolated structures. According to these documents, two methods are proposed to study the inelastic response of the structure in elevation: (a) Nonlinear Response History Analysis; (b) Nonlinear Static Analysis. According to FEMA 356 [38] and UBC 97 [39], the pushover analysis may also be used for the seismic analysis of isolated structures. On the contrary, both European standards [2] and Italian Seismic Code [1] do not allow the use of the pushover analysis in the case of base-isolated buildings, while they permit the use of time-history analysis. Moreover, it must be observed that the base-isolated structures are generally nonclassically damped since strong differences between the internal mechanism of energy dissipation occur. Thus, as an alternative to direct integration methods, the dynamic equilibrium equation may be uncoupled in the complex modal space. The complex mode superposition can give several advantages for the evaluation of seismic response, and it was found to be competitive in terms of computational effort with direct integration methods [41]. As an alternative, Muscolino et al. [42] proposed an improved response spectrum method (RSM) for the seismic analysis and design of building structures with base isolation system. This method consists of a two-stage transformation of coordinates in parallel with a Damping-Adjusted Combination (DAC) rule. Thus, it avoids the calculation of the exact complex-valued eigenproperties of base-isolated buildings and reduces computational effort. Moreover, it addresses the main sources of inaccuracy in the practical application of the RSM to base-isolated buildings, that is, response spectrum for different viscous damping ratios and combination rule for nonconventional structures. The direct integration methods may be used for the solution of the equations of motion whenever they are coupled. This approach requires the solution of a system of differential equations whose size is equal to the total number of degrees of freedom of the structure. In this paper, the Fast Nonlinear Analysis Method [43] was used for the integration of the equations of motion. This method based on an iterative vector superposition algorithm was found to be extremely efficient in the case of isolated structures since a very limited number of points in which nonlinear behavior takes place when subjected to seismic loading occur. Moreover, significant reductions in processing times were found when compared with other nonlinear analysis methods. Thus, the timedependent response of the structure was obtained by direct numerical integration of its differential equations of motion. The seismic response was evaluated by means of nonlinear time-history analysis, using a constitutive law of the isolation bearings which can adequately reproduce the behavior of the system in the range of deformations and velocities anticipated in the seismic design situation. In particular, the constitutive law of the isolation bearings was approximated by the well-known Bouc-Wen model [44, 45]. The seismic motion consisted of two simultaneously acting accelerograms simultaneously along both horizontal directions. In the case of base-isolated structures, it is possible to use a single acceleration time-history. However, in this paper, a group of 7 pairs of time-histories was applied, in accordance with the Italian Code requirements for fixed-base structures. Thus, the average of the response quantities from all the analyses was
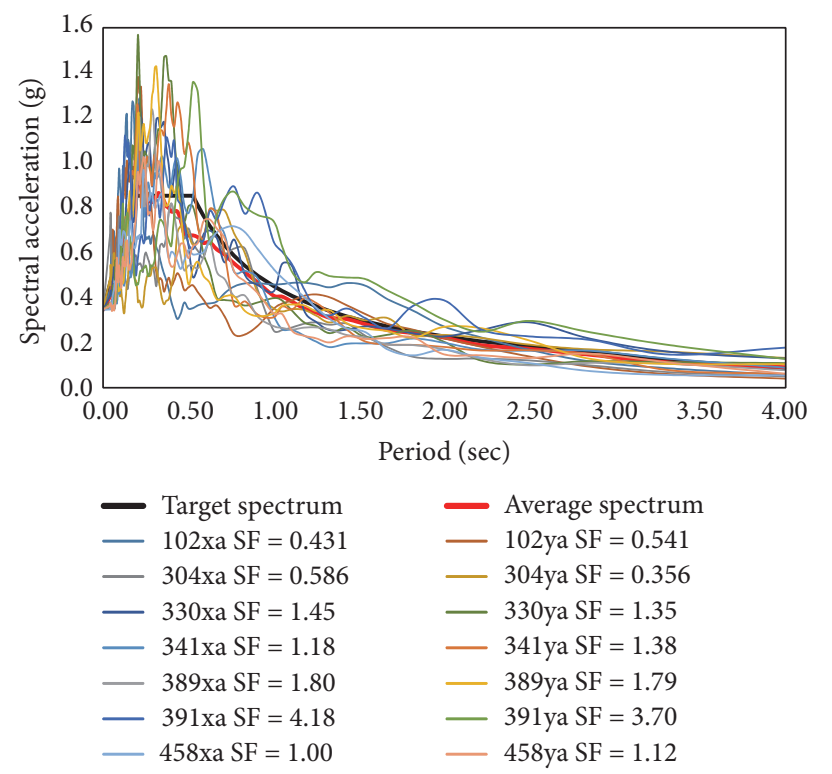

FIGURE 19: Spectrum compatibility for the selected records.

used as the design value of the seismic effect in the relevant verifications. The description of the seismic motion may be made by using artificial accelerograms and recorded or simulated accelerograms. The recorded accelerograms allow accounting for characteristics like frequency, duration, and energy of real earthquake ground motions. The SIMBAD database (Selected Input Motions for displacement-Based Assessment and Design) [46] was used for selecting the recorded accelerograms from different worldwide strong ground motion databases [47]. The suite of accelerograms observed the rules recommended in the seismic standards. In fact, the mean of the zero period spectral response acceleration values (calculated from the individual timehistories) was not smaller than the value of $a_{g} \cdot S$ for the site in question, where $a_{g}$ is the design ground acceleration on type A ground and $S$ is the soil factor. Furthermore, in the range of periods between $0.2 T_{\text {ISO }}$ and $1.2 T_{\text {ISO }}$, no value of the mean 5\% damping elastic spectrum, calculated from all time-histories was less than $90 \%$ of the corresponding value of the 5\% damping elastic response spectrum. The recorded accelerograms considered in the numerical analysis are summarized in Table 6. In Figure 19, the spectrum compatibility for the selected acceleration records was represented. The same figure provides the scale factors of the selected ground motion records.

4.2. Evaluation of Torsional Effects. The lateral-torsional response of structures was extensively studied in the literature [5, 25-27, 48-52]. The effectiveness of base isolation is reduced for a high eccentricity of the superstructure. However, the eccentricity of the superstructure does not have any significant influence on base displacements. On the contrary, the eccentricity of the centre of mass on the isolation plane may increase the lateral displacement of the isolation devices. Although the magnitude of shear and 
TABLE 6: Set of earthquake natural records.

\begin{tabular}{lcccccc}
\hline Waveform ID & Earthquake ID & Earthquake name & Date & $M_{w}$ & $\mathrm{PGA}_{x}\left[\mathrm{~m} / \mathrm{s}^{2}\right]$ & $\mathrm{PGA}_{y}\left[\mathrm{~m} / \mathrm{s}^{2}\right]$ \\
\hline 389 & 149 & Christchurch & 13.06 .2011 & 6.0 & 1.8787 & 2.8872 \\
341 & 142 & Christchurch & 21.02 .2011 & 6.2 & 2.8548 & 2.4537 \\
330 & 137 & Darfield & 03.09 .2003 & 7.1 & 2.3292 & 2.508 \\
102 & 31 & Bam & 26.12 .2003 & 6.6 & 7.8338 & 5.2357 \\
304 & 94 & Loma Prieta & 18.10 .1989 & 6.9 & 5.758 & 3.4759 \\
458 & 99 & Northridge & 17.01 .1994 & 6.7 & 3.3738 & 3.021 \\
391 & 149 & Christchurch & 13.06 .2011 & 6.0 & 0.8071 & 0.91367 \\
\hline
\end{tabular}

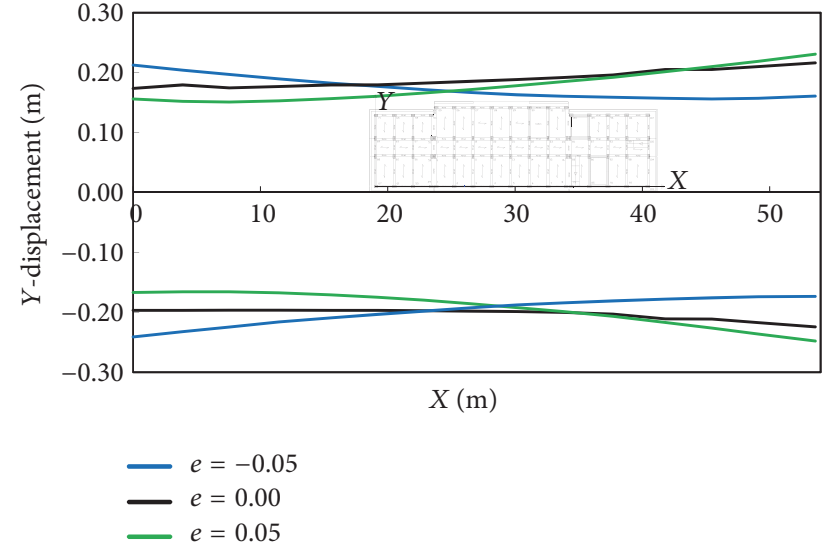

FIgURE 20: Average of the maximum $Y$-displacements (accidental eccentricity $e=+0.05, e=+0.00, e=-0.05)$.

torque generated in an elastomeric isolated structure is less than that of the fixed-base structure, in general, the torsional amplifications cannot be ignored. In particular, torsion leads to significantly increased isolator deformations especially if large rotations and large lateral deformations at the centre of mass occur at or very near to the same time during the earthquake. The main source of torsional motions in seismically isolated buildings is the eccentricity between the centre of the stiffness of the isolation system and the centre of mass of the structure. Furthermore, the centre of mass CM should be shifted creating an eccentricity $e / L= \pm 0.05$ that is the worldwide assumed code value for multistorey buildings. In this study, a complex 3D model was used for the baseisolated building. Thus, the structural eccentricity does not appear as such and it is, therefore, more difficult to account for its effects. Moreover, the diaphragmatic behavior at storey level in elevation is not ensured since the superstructure is composed of three parts disconnected by the separation gaps at each storey. Since the mass is generated from the load patterns, an accidental eccentricity was created acting on the mass multipliers to deal with these torsional effects. In Figure 20, the $Y$-displacement pattern of the isolation plane is plotted. The analysis results were estimated as the average of the maximum displacements from the seven pairs of the selected time-histories. The results help clarify that torsional effects are significant, even though the centre of the stiffness of the isolation system and the centre of mass of the structure almost coincide. In fact, the value of the lateral displacement on the flexible side is greater than $35 \%$ compared to that in the centre of mass of the building. This result depends on the high slenderness ratio (height to base ratio) of the building in plan $\left(\lambda=L_{\max } / L_{\min }=3.26\right)$ which increases the accidental torsional effects. In Figure 21(a), a sample plot of $Y$-displacement versus $X$-displacement of a rubber isolation bearing located on the flexible side is shown. The results refer to waveform N.389 and accidental eccentricity $e=+0.05$. In Figure 21(b), a sample plot of the hysteretic response ( $Y$ Shear versus $Y$-displacement) of a $800 \mathrm{~mm}$ rubber isolator is displaced. In Table 7 is summarized the information about the force and displacement in the isolation rubber bearings. The average of the response quantities from the analyses under 7 pairs of time-histories was shown. In particular, the maximum displacement in $X$ - and $Y$-directions and the maximum and minimum vertical seismic loads are plotted. It can be observed that the minimum vertical seismic load $\left(N_{\min }\right)$ is always positive. This means that the isolation bearings are all in compression for all the load combinations. Moreover, the maximum vertical seismic load $\left(N_{\max }\right)$ is always lower than the corresponding nominal value ( $V=$ maximum vertical seismic load in Table 3). Finally, the maximum displacement is always lower than the horizontal design displacement $\left(d_{d c}=350 \mathrm{~mm}\right)$.

4.3. Evaluation of Pounding Effects. Past earthquakes have revealed detrimental pounding effects of the seismic performance of buildings, ranging from light local damage to more severe structural failure. The case study is a multiple building structure with a common ground floor and seismic separation gaps used to separate the three main blocks in elevation. This paper investigates, through numerical simulations, the potential poundings of the three adjacent superstructures. To this aim, the live loads were placed on the floors of the three superstructures in such a way to maximize the torsional effects. In particular, two different dispositions of the live loads were used (Figure 22). The relative displacements were calculated by means of the nonlinear time-history analysis under the seven pairs of the selected time-histories scaled to the intensity of the Life Safety Limit State. The maximum relative $x$-displacement was computed for the suite of seven natural ground motions. In Figure 22, the average of the lateral displacement in $X$-direction (where pounding can occur) from all these analyses was plotted. The possibility of poundings between the superstructures $A$ and $B$ may be clearly excluded. In fact, the maximum relative displacement 
TABLE 7: Force and displacements in isolation rubber bearings.

\begin{tabular}{lccccccccccc}
\hline ID & Device & Displ. $X(\mathrm{~m})$ & Displ. $Y(\mathrm{~m})$ & $\begin{array}{c}N_{\max } \\
\mathrm{kN}\end{array}$ & $\begin{array}{c}N_{\min } \\
\mathrm{kN}\end{array}$ & ID & Device & $\begin{array}{c}\text { Displ. } X(\mathrm{~m}) \\
\text { Displ. } Y(\mathrm{~m})\end{array} \begin{array}{c}N_{\max } \\
\mathrm{kN}\end{array} \begin{array}{c}N_{\min } \\
\mathrm{kN}\end{array}$ \\
\hline 71 & SI-S 800/180 & 0.216 & 0.240 & 801.17 & 259.08 & 62 & SI-S 800/180 & 0.221 & 0.232 & 1141.3 & 593.45 \\
59 & SI-S 650/180 & 0.216 & 0.224 & 693.18 & 330.63 & 56 & SI-S 650/180 & 0.221 & 0.224 & 908.92 & 542.60 \\
26 & SI-S 600/168 & 0.216 & 0.215 & 703.17 & 383.69 & 14 & SI-S 600/168 & 0.221 & 0.203 & 847.99 & 524.82 \\
28 & SI-S 600/168 & 0.216 & 0.198 & 776.74 & 457.23 & 15 & SI-S 650/180 & 0.221 & 0.206 & 940.08 & 573.77 \\
29 & SI-S 600/168 & 0.216 & 0.199 & 863.94 & 544.40 & 104 & SI-S 800/180 & 0.221 & 0.247 & 1254.7 & 707.38 \\
30 & SI-S 600/168 & 0.216 & 0.202 & 878.06 & 558.51 & 67 & SI-S 800/180 & 0.226 & 0.240 & 979.38 & 427.22 \\
31 & SI-S 600/168 & 0.216 & 0.206 & 875.56 & 556.05 & 61 & SI-S 800/180 & 0.226 & 0.231 & 1134.6 & 582.11 \\
32 & SI-S 600/168 & 0.216 & 0.211 & 591.79 & 282.16 & 55 & SI-S 650/180 & 0.226 & 0.224 & 856.27 & 487.12 \\
95 & SI-S 650/180 & 0.216 & 0.226 & 660.95 & 298.34 & 2 & SI-S 600/168 & 0.226 & 0.209 & 714.49 & 388.75 \\
107 & SI-S 800/180 & 0.216 & 0.250 & 881.35 & 339.25 & 4 & SI-S 600/168 & 0.226 & 0.198 & 850.78 & 525.00 \\
63 & SI-S 800/180 & 0.219 & 0.232 & 947.71 & 402.43 & 5 & SI-S 600/168 & 0.226 & 0.199 & 951.86 & 626.05 \\
19 & SI-S 600/168 & 0.219 & 0.203 & 802.85 & 481.21 & 6 & SI-S 650/180 & 0.226 & 0.202 & 1001.2 & 631.89 \\
23 & SI-S 650/180 & 0.219 & 0.206 & 945.62 & 581.00 & 7 & SI-S 650/180 & 0.226 & 0.206 & 872.76 & 503.54 \\
93 & SI-S 650/180 & 0.219 & 0.226 & 722.78 & 358.18 & 97 & SI-S 800/180 & 0.226 & 0.235 & 1068.3 & 515.74 \\
105 & SI-S 800/180 & 0.218 & 0.247 & 1113.3 & 568.55 & 103 & SI-S 800/180 & 0.226 & 0.247 & 1101.6 & 549.39 \\
\hline
\end{tabular}

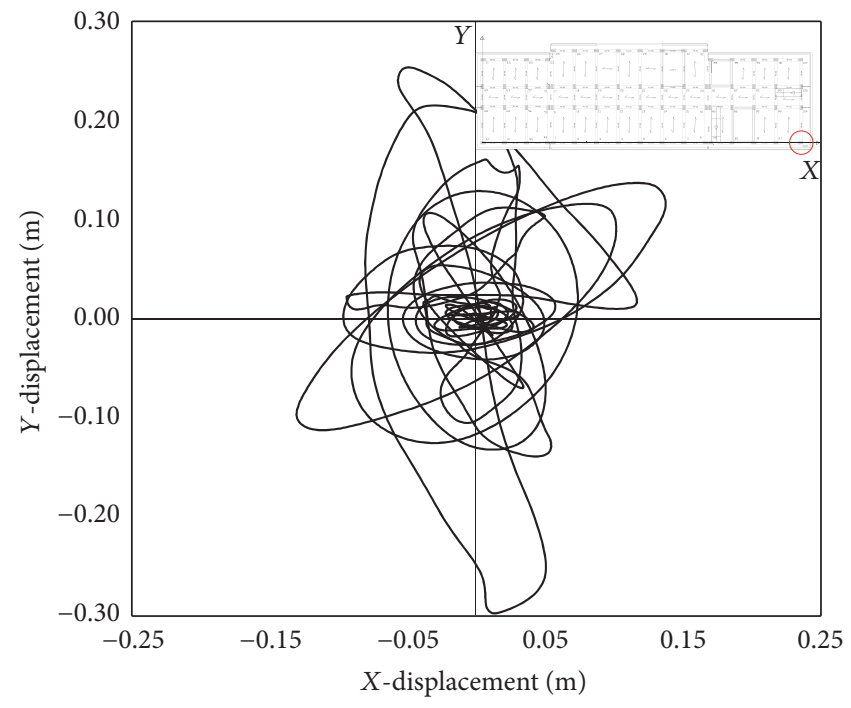

(a)

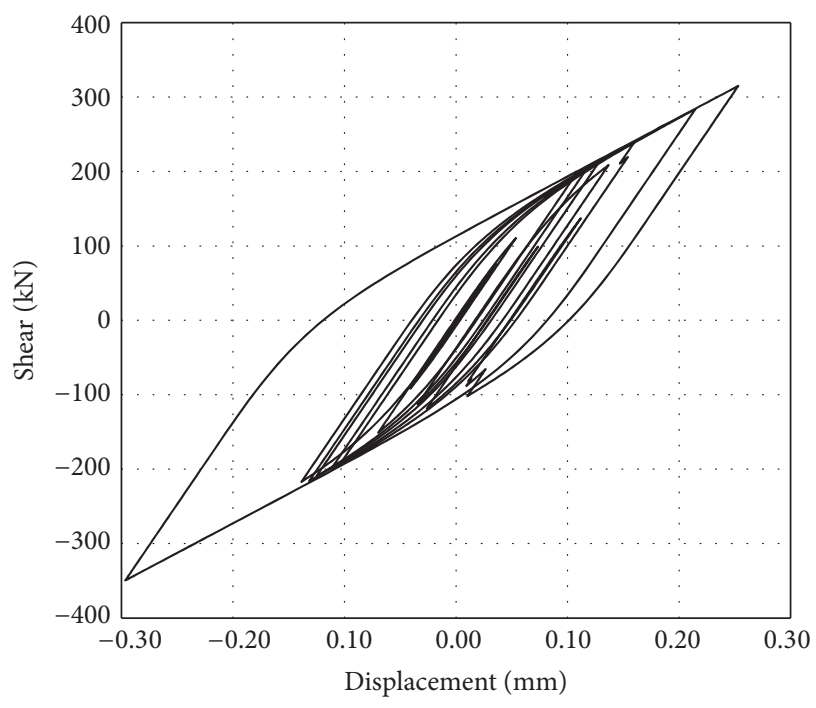

(b)

Figure 21: (a) $Y$-displacement versus $X$-displacement. (b) $Y$-Shear versus $Y$-displacement. Waveform N.389. Accidental eccentricity $e=$ +0.05 .

(equal to $4.5 \mathrm{~mm}$ ) is very low if compared to the seismic separation gap between the adjacent superstructures (equal to $3 \mathrm{~cm}$ ).

\section{Conclusions}

The analysis and design of an existing multiple building structure seismic retrofitted by a base isolation system incorporating rubber bearings and Sliding Devices were presented in the paper. The retrofitting design and the installation phases of the seismic isolation bearings were described in detail. The results from nonlinear time-history analysis were reported in this paper. The earthquake response analysis of the hospital building was performed chiefly with reference to the horizontal displacements of the isolation plane and the relative displacements of the three structures in elevation. The value of the maximum lateral displacement on the flexible side of the isolation plane was greater than 35\% compared to that in the centre of mass. The results showed significant torsional effects even though the plan layout of the isolation system was designed in such a way to minimize the eccentricity between the centre of mass of the building and the centre of the stiffness of the base isolation system. The possibility of poundings between the adjacent structures in elevation during strong earthquakes was thoroughly investigated. To this aim, the maximum relative displacement in the direction 


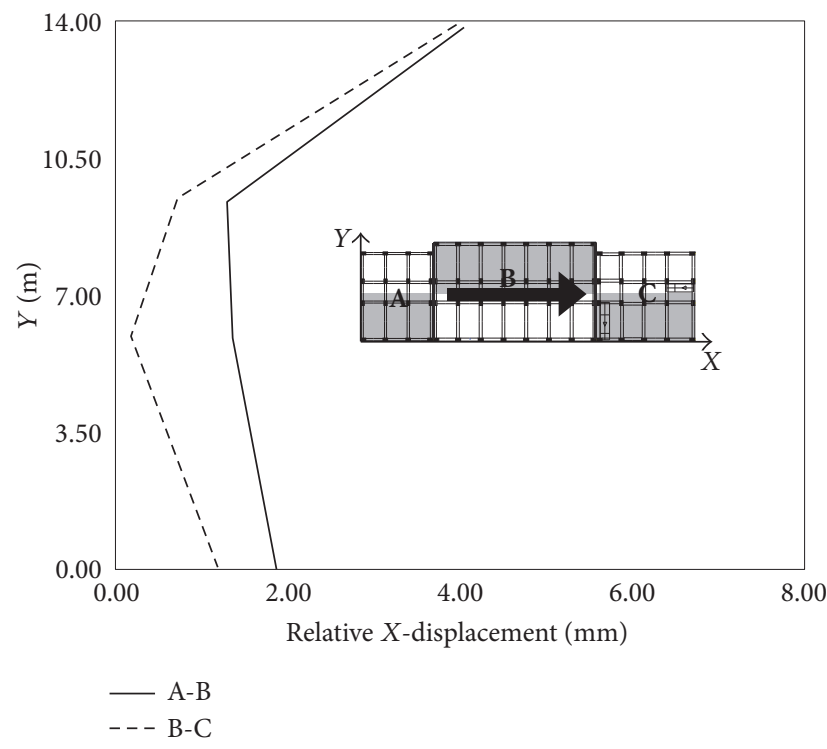

(a)

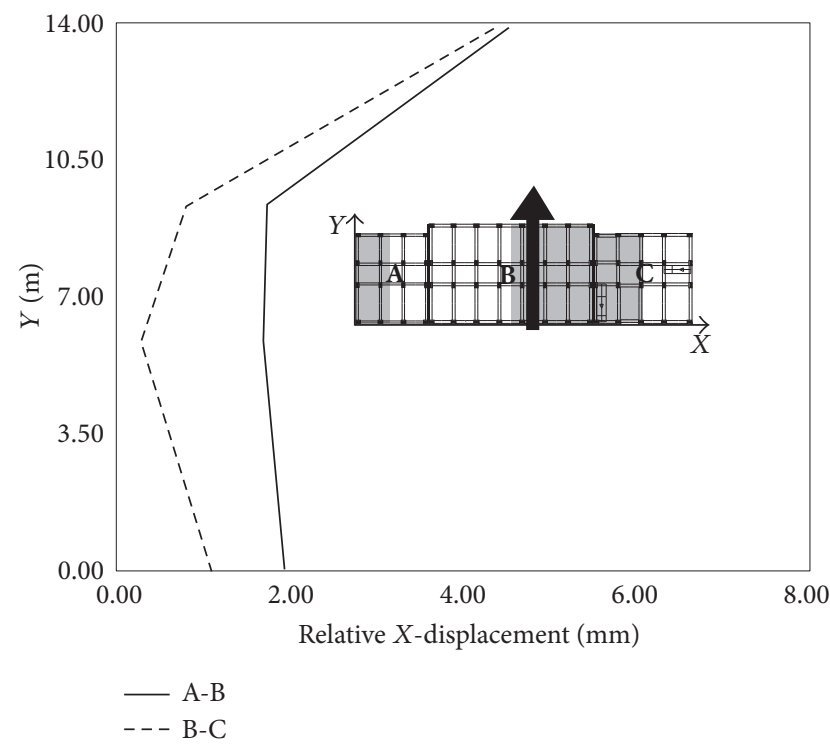

(b)

FIgURE 22: Mean of maximum relative $X$-displacement between adjacent superstructures.

where pounding can occur was compared to the minimum separation gap required to prevent pounding. It was found that the maximum relative displacement was very low if compared to the seismic separation gap provided between the adjacent superstructures.

Compared to traditional retrofitting techniques, the seismic isolation of the building proved to give several advantages. First of all, the conventional retrofitting methods are based on the increase of the capacity on the structure, in terms of ductility, stiffness, and strength, to meet the likely demand. So they require addition of new structural elements and strengthening the existing members, thus involving extensive modifications of the building at all levels with the consequent loss of its functionality. On the contrary, the seismic isolation of the building has reduced the seismic forces demand on the superstructures and offered a great deal of protection to everything above the base isolation plane without extensive strengthening interventions on the structural members. Most construction work has been confined under the isolation plane, thus maintaining the functionality of the building in elevation. Moreover, the seismic isolation has given a strong reduction of the interstorey drift in superstructures when compared to the fixed-base structures. Thus, the width of the separation gaps has been found quite adequate for protection against pounding. Finally, it must be pointed out that the anchors in the column to attach the temporary propping have remained in place and may be reused for future interventions of maintenance and/or replacement of the bearings. The main limit of the proposed retrofitting technique is that to maintain stability of the elastomeric bearings under large lateral displacements and their diameters are large. The increase in bearing diameter has resulted in stiffer bearings, making it necessary to use flat sliding bearings in combination with the elastomeric bearings. Moreover, unlike the FPS bearings, the natural period of the isolated structure depends on the mass of the superstructure. Thus, if significant changes of the design loads will occur, the seismic isolation system built now will have to be retrofitted.

\section{Notation}

$a_{g}:$ Design ground acceleration on type A ground

$b$ : Width of compression zone

C: Coefficient of seismic intensity of Italian Code

CF: Confidence factor

$d_{b}$ : Mean diameter of the tension reinforcement in r.c. member

$d_{d c}:$ Design displacement of isolation bearing

$d_{t}^{*}$ : Target displacement of equivalent SDOF system

$D_{g}:$ Diameter of isolation rubber bearing

$e_{a i}:$ Accidental eccentricity

$f_{c}: \quad$ Concrete compressive strength

$f_{y}$ : Tensile strength of steel rebar (MPa)

$f_{c m}$ : Mean value of concrete compressive strength

$f_{y m}$ : Mean value of tensile strength of steel rebar

$F_{0}$ : Amplification factor

$G_{\text {din }}$ : Dynamic shear modulus of isolation rubber bearing

$G_{\text {stat }}:$ Static shear modulus of isolation rubber bearing

$h$ : Total height of isolation rubber bearing without anchor plates

$H$ : Total height of isolation rubber bearing with anchor plates

I: $\quad$ Importance factor 
$K_{e}: \quad$ Effective lateral stiffness of isolation rubber bearing

$K_{v}$ : $\quad$ Vertical stiffness of isolation rubber bearing

$L_{i}: \quad$ Floor dimension at storey $i$ perpendicularly to the direction of the acting seismic action

$L_{V}$ : Ratio moment/shear at the end section

$M_{w}$ : Moment magnitude of earthquake ground motion

$M_{a i}$ : Torsional moment applied at storey $i$

$N: \quad$ Axial force (positive for compression)

$N_{\text {max }}: \quad$ Maximum vertical seismic load in isolation rubber bearing

$N_{\text {min }}$ : Minimum vertical seismic load in isolation rubber bearing

$P_{V R}: \quad$ Probability of exceedance

PGA: Peak ground acceleration on type A ground

$\mathrm{PGA}_{\mathrm{IO}}^{d}$ : Reference peak ground acceleration demand on type A ground at the Immediate Occupancy (IO) Limit State

$\mathrm{PGA}_{\mathrm{DL}}^{d}$ : Reference peak ground acceleration demand on type A ground at the Damage Limitation (DL) Limit State

$\mathrm{PGA}_{\mathrm{LS}}^{d}$ : Reference peak ground acceleration demand on type A ground at the Life Safety (LS) Limit State

$\mathrm{PGA}_{\mathrm{CP}}^{d}$ : Reference peak ground acceleration demand on type A ground at the Collapse Prevention (CP) Limit State

$\mathrm{PGA}_{\mathrm{IO}}^{c}$ : Peak ground acceleration capacity on type A ground at the Immediate Occupancy

(IO) Limit State

$\mathrm{PGA}_{\mathrm{DL}}^{c}$ : Peak ground acceleration capacity on type A ground at the Damage Limitation (DL) Limit State

$\mathrm{PGA}_{\mathrm{LS}}^{c}$ : Peak ground acceleration capacity on type A ground at the Life Safety (LS) Limit State

$\mathrm{PGA}_{\mathrm{CP}}^{c}$ : Peak ground acceleration capacity on type A ground at the Collapse Prevention (CP) Limit State

$s_{h}: \quad$ Stirrup spacing

$S_{a}: \quad$ Spectral acceleration

$S_{d}: \quad$ Spectral displacement

$S_{1}$ : $\quad$ Primary shape factor of isolation rubber bearing

$S_{2}$ : $\quad$ Secondary shape factor of isolation rubber bearing

S: $\quad$ Soil factor

$S_{T}: \quad$ Topographic amplification factor

$t_{e}: \quad$ Total rubber thickness of isolation bearing

$T_{C}$ : Transition Period

$T_{\text {ISO }}$ : Fundamental period of isolated building

$T_{R}: \quad$ Return period

$V: \quad$ Maximum vertical seismic load

$V_{\text {SLU }}: \quad$ Maximum vertical design load

$V_{S, 30}$ : Average value of propagation velocity of $S$-waves in the upper $30 \mathrm{~m}$
$W$ : Weight without anchor bolts of rubber bearing

$Z$ : Side length of anchor plates

$\alpha$ : Confinement effectiveness factor

$\alpha_{x}$ : Modal mass ratio in $x$-direction

$\alpha_{y}$ : Modal mass ratio in $y$-direction

$\phi_{y}$ : Yield curvature of the end section of beams and columns

$\lambda$ : Slenderness ratio of the building in plan (height to base ratio)

$v$ : Normalized axial force

$\theta_{u}$ : Total chord rotation capacity

$\rho_{d}$ : Steel ratio of diagonal reinforcement in each diagonal direction

$\rho_{s x}$ : Ratio of transverse steel parallel to $x$-direction of loading

$\xi$ : $\quad$ Viscous damping ratio

$\omega$ : Mechanical reinforcement ratio of tension longitudinal reinforcement

$\omega^{\prime}$ : Mechanical reinforcement ratio of compression longitudinal reinforcement.

\section{Competing Interests}

The authors declare that they have no competing interests.

\section{Acknowledgments}

The author express their personal appreciation for the valuable assistance given to them in the construction site by Fabio Formato and Alberto Maria Avossa (Design Engineers), Giovambattista Aquilino Musto (Construction Manager), Sergio Casarella (Testing Manager), and Vincenzo Botticelli (Technical Manager of MUCAFER Enterprise).

\section{References}

[1] NTC 2008, "Norme Tecniche per le Costruzioni," D.M. Infrastrutture Trasporti 14 gennaio 2008 (Italian).

[2] Comité Européen de Normalisation (CEN), Eurocode 8Design Provisions for Earthquake Resistance of Structures, European Communities for Standardization, Brussels, Belgium, 2004.

[3] S. Sorace and G. Terenzi, "Analysis, design, and construction of a base-isolated multiple building structure," Advances in Civil Engineering, vol. 2014, Article ID 585429, 13 pages, 2014.

[4] L. Di Sarno, E. Chioccarelli, and E. Cosenza, "Seismic response analysis of an irregular base isolated building," Bulletin of Earthquake Engineering, vol. 9, no. 5, pp. 1673-1702, 2011.

[5] V. Kilar and D. Koren, "Seismic behaviour of asymmetric base isolated structures with various distributions of isolators," Engineering Structures, vol. 31, no. 4, pp. 910-921, 2009.

[6] F. Mazza, A. Vulcano, and M. Mazza, "Nonlinear dynamic response of RC buildings with different base Isolation systems subjected to horizontal and vertical components of near-fault ground motions," The Open Construction \& Building Technology Journal, vol. 6, pp. 373-383, 2012.

[7] V. A. Zayas, S. S. Low, and S. A. Mahin, "The FPS earthquake resisting system," Experimental Report UCB/EERC 87/01, EERC, University of California, Berkeley, Calif, USA, 1987. 
[8] A. Mokha, M. Constantinou, and A. Reinhorn, "Teflon bearings in base isolation I: testing," Journal of Structural Engineering, vol. 116, no. 2, pp. 438-454, 1990.

[9] M. Constantinou, A. Mokha, and A. Reinhorn, "Teflon bearings in base isolation. II: modeling," Journal of Structural Engineering, vol. 116, no. 2, pp. 455-474, 1990.

[10] D. M. Fenz and M. C. Constantinou, "Spherical sliding isolation bearings with adaptive behavior: theory," Earthquake Engineering and Structural Dynamics, vol. 37, no. 2, pp. 163-183, 2008.

[11] D. M. Fenz and M. C. Constantinou, "Spherical sliding isolation bearings with adaptive behavior: experimental verification," Earthquake Engineering and Structural Dynamics, vol. 37, no. 2, pp. 185-205, 2008.

[12] D. M. Fenz and M. C. Constantinou, "Modeling triple friction pendulum bearings for response-history analysis," Earthquake Spectra, vol. 24, no. 4, pp. 1011-1028, 2008.

[13] R. S. Jangid, "Optimum friction pendulum system for near-fault motions," Engineering Structures, vol. 27, no. 3, pp. 349-359, 2005.

[14] C. S. Tsai, B.-J. Chen, W. S. Pong, and T.-C. Chiang, "Interactive behavior of structures with multiple friction pendulum isolation system and unbounded foundations," Advances in Structural Engineering, vol. 7, no. 6, pp. 539-550, 2004.

[15] T. C. Becker and S. A. Mahin, "Experimental and analytical study of the bi-directional behavior of the triple friction pendulum isolator," Earthquake Engineering and Structural Dynamics, vol. 41, no. 3, pp. 355-373, 2012.

[16] F. Naeim and J. M. Kelly, Design of Seismic Isolated Structures, John Wiley \& Sons, New York, NY, USA, 1999.

[17] M. Dolce, D. Cardone, and F. C. Ponzo, "Shaking-table tests on reinforced concrete frames with different isolation systems," Earthquake Engineering \& Structural Dynamics, vol. 36, no. 5, pp. 573-596, 2007.

[18] C.-F. Han, C.-X. Li, and Q.-H. Zhang, "Experimental seismic study of concrete structures with base and roof isolation systems," Journal of Earthquake Engineering and Engineering Vibration, vol. 24, no. 1, pp. 141-147, 2004.

[19] S. Nagarajaiah and S. Xiaohong, "Response of base-isolated USC hospital building in Northridge earthquake," Journal of Structural Engineering, vol. 126, no. 10, pp. 1177-1186, 2000.

[20] T. Fujita, Demonstration of Effectiveness of Seismic Isolation in the Hanshin-Awaji Earthquake and Progress of Applications of Base-Isolated Buildings, Report on the January 1995, Kobe Earthquake, Institute of Industrial Science, University of Tokyo, Tokyo, Japan, 1999.

[21] T. Holmes and P. Somers, "Northridge earthquake of 17 January 1994, reconnaissance report," Earthquake Spectra, vol. 11, pp. 243-251, 1996.

[22] A. B. M. S. Islam, M. Z. Jumaat, R. Ahmmad, and K. M. ud Darain, "Retrofitting of vulnerable RC structures by base isolation technique," Earthquake and Structures, vol. 9, no. 3, pp. 603-623, 2015.

[23] V. A. Matsagar and R. S. Jangid, "Base isolation for seismic retrofitting of structures," Practice Periodical on Structural Design and Construction, vol. 13, no. 4, pp. 175-185, 2008.

[24] P. C. Tsopelas, S. Nagarajaiah, M. C. Constantinou, and A. M. Reinhorn, "Nonlinear dynamic analysis of multiple building base isolated structures," Computers \& Structures, vol. 50, no. 1, pp. 47-57, 1994.

[25] A. Tena-Colunga and C. Zambrana-Rojas, "Dynamic torsional amplifications of base-isolated structures with an eccentric isolation system," Engineering Structures, vol. 28, no. 1, pp. 7283, 2006.

[26] A. Tena-Colunga and J. L. Escamilla-Cruz, "Torsional amplifications in asymmetric base-isolated structures," Engineering Structures, vol. 29, no. 2, pp. 237-247, 2007.

[27] C. E. Seguin, J. L. Almazán, and J. C. De la Llera, “Torsional balance of seismically isolated asymmetric structures," Engineering Structures, vol. 46, pp. 703-717, 2013.

[28] E. D. Wolff, C. Ipek, M. C. Constantinou, and L. Morillas, "Torsional response of seismically isolated structures revisited," Engineering Structures, vol. 59, pp. 462-468, 2014.

[29] D.M. LL.PP. 24/01/1986, Ministerial Decree, Norme tecniche per le costruzioni in zone sismiche, 1986 (Italian).

[30] CSI Computer \& Structures Inc. SAP2000, Linear and Nonlinear Static and Dynamic Analysis of Three-Dimensional Structures, CSI Computer \& Structures Inc, Berkeley, Calif, USA, 2015.

[31] J. B. Mander, M. J. Priestley, and R. Park, "Theoretical stressstrain model for confined concrete," Journal of Structural Engineering, vol. 114, no. 8, pp. 1804-1826, 1988.

[32] P. Fajfar, "Capacity spectrum method based on inelastic demand spectra," Earthquake Engineering and Structural Dynamics, vol. 28, no. 9, pp. 979-993, 1999.

[33] M. Ferraioli, A. M. Avossa, A. Lavino, and A. Mandara, "Accuracy of advanced methods for nonlinear static analysis of steel moment-resisting frames," Open Construction and Building Technology Journal, vol. 8, pp. 310-323, 2014.

[34] T. Vidic, P. Fajfar, and M. Fischinger, "Consistent inelastic design spectra: strength and displacement," Earthquake Engineering \& Structural Dynamics, vol. 23, no. 5, pp. 507-521, 1994.

[35] M. Ferraioli, A. M. Avossa, and F. Formato, "Base isolation seismic retrofit of a hospital building in Italy: design and construction," in Proceedings of the Final Conference on COST Action C26: Urban Habitat Constructions under Catastrophic Events, pp. 835-840, September 2010.

[36] M. Ferraioli, R. Costanzo, and A. Lavino, "Base isolation seismic retrofit of a hospital building in Italy: performance under earthquake strong ground motions," in Proceedings of the Final Conference on COST Action C26: Urban Habitat Constructions under Catastrophic Events, pp. 841-846, September 2010.

[37] M. Ferraioli, A. Lavino, and A. Mandara, "Behaviour factor of code-designed steel moment-resisting frames," International Journal of Steel Structures, vol. 14, no. 2, pp. 243-254, 2014.

[38] Federal Emergency Management Agency, Prestandard and Commentary for the Seismic Rehabilitation of Buildings, FEMA 356, The American Society of Civil Engineers for the Federal Emergency Management Agency, Washington, DC, USA, 2000.

[39] Uniform Building Code, "Structural engineering design provisions," in Proceedings of the International Conference of Building Officials, Whittier, Calif, USA, 1997.

[40] Federal Emergency Management Agency, Recommended Provisions for Seismic Regulations for New Buildings and Other Structures, FEMA 450, The Building Seismic Safety Council for the Federal Emergency Management Agency, Washington, DC, USA, 2003.

[41] P. Malangone and M. Ferraioli, "A modal procedure for seismic analysis of non-linear base-isolated multistorey structures," Earthquake Engineering and Structural Dynamics, vol. 27, no. 4, pp. 397-412, 1998.

[42] G. Muscolino, A. Palmeri, and C. Versaci, "Damping-adjusted combination rule for the response spectrum analysis of baseisolated buildings," Earthquake Engineering and Structural Dynamics, vol. 42, no. 2, pp. 163-182, 2013. 
[43] P. Leger, E. L. Wilson, and R. W. Clough, "The use of load dependent vectors for dynamic and earthquake analyses," Tech. Rep. UCB/EERC-86/04, Berkeley University, 1986.

[44] Y.-K. Wen, "Method for random vibration of hysteretic systems," Journal of Engineering Mechanical Division, vol. 102, no. 2, pp. 249-263, 1976.

[45] H.-G. Li and G. Meng, "Nonlinear dynamics of a SDOF oscillator with Bouc-Wen hysteresis," Chaos, Solitons and Fractals, vol. 34, no. 2, pp. 337-343, 2007.

[46] C. Smerzini and R. Paolucci, "Research Project DPC-RELUIS 2010-2013," in SIMBAD: A Database with Selected Input Motions for Displacement-Based Assessment and Design-2nd Release, Department of Structural Engineering, Politecnico di Milano, Milano, Italy, 2011.

[47] I. Iervolino, C. Galasso, and E. Cosenza, "REXEL: computer aided record selection for code-based seismic structural analysis," Bulletin of Earthquake Engineering, vol. 8, no. 2, pp. 339362, 2010.

[48] M. Ferraioli, "Case study of seismic performance assessment of irregular RC buildings: hospital structure of Avezzano (L'Aquila, Italy)," Earthquake Engineering and Engineering Vibration, vol. 14, no. 1, pp. 141-156, 2015.

[49] M. Ferraioli, "Inelastic torsional response of an asymmetricplan hospital building in Italy," in Proceedings of the Final Conference COST ACTION C26: Urban Habitat Constructions under Catastrophic Events, pp. 365-370, September 2010.

[50] M. Ferraioli, D. Abruzzese, L. Miccoli, A. Vari, and G. Di Lauro, "Structural identification from environmental vibration testing of an asymmetric-plan hospital building in Italy," in COST ACTION C26: Urban Habitat Constructions under Catastrophic Events-Proceedings of the Final Conference, pp. 981-986, 2010.

[51] D. Basu and S. K. Jain, "Seismic analysis of asymmetric buildings with flexible floor diaphragms," Journal of Structural Engineering, vol. 130, no. 8, pp. 1169-1176, 2004.

[52] M. Ferraioli and A. Mandara, "Base isolation for seismic retrofitting of a multiple building structure: evaluation of equivalent linearization method," Mathematical Problems in Engineering, vol. 2016, Article ID 8934196, 17 pages, 2016. 


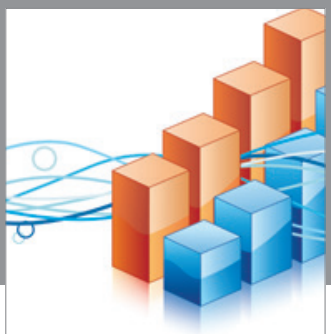

Advances in

Operations Research

vatem alat4

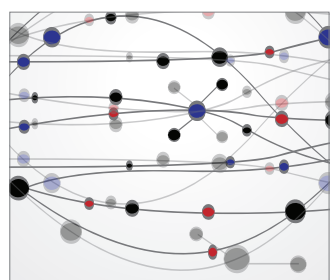

\section{The Scientific} World Journal
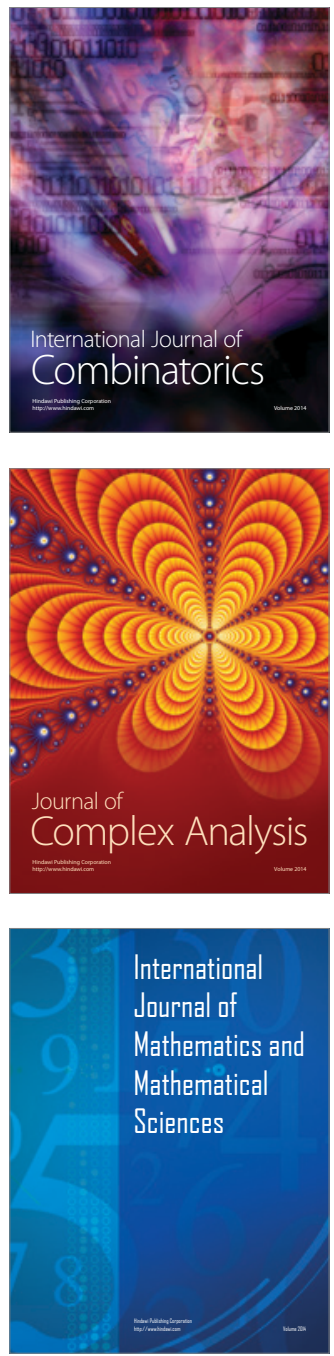
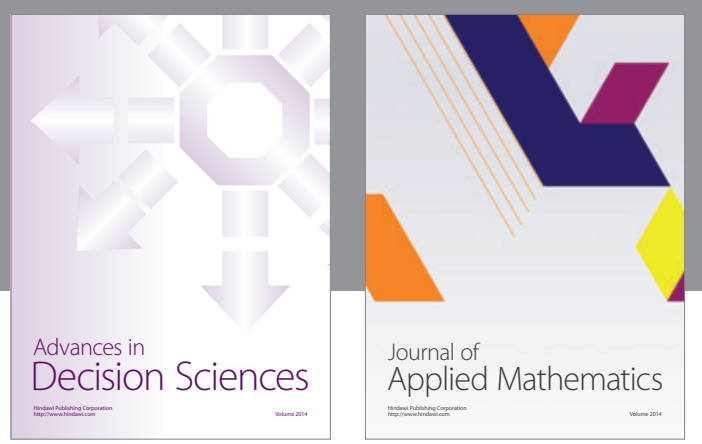

Algebra

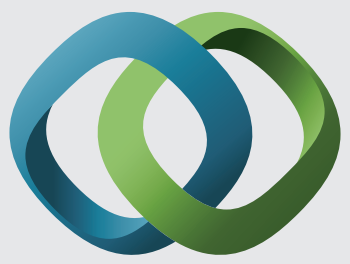

\section{Hindawi}

Submit your manuscripts at

https://www.hindawi.com
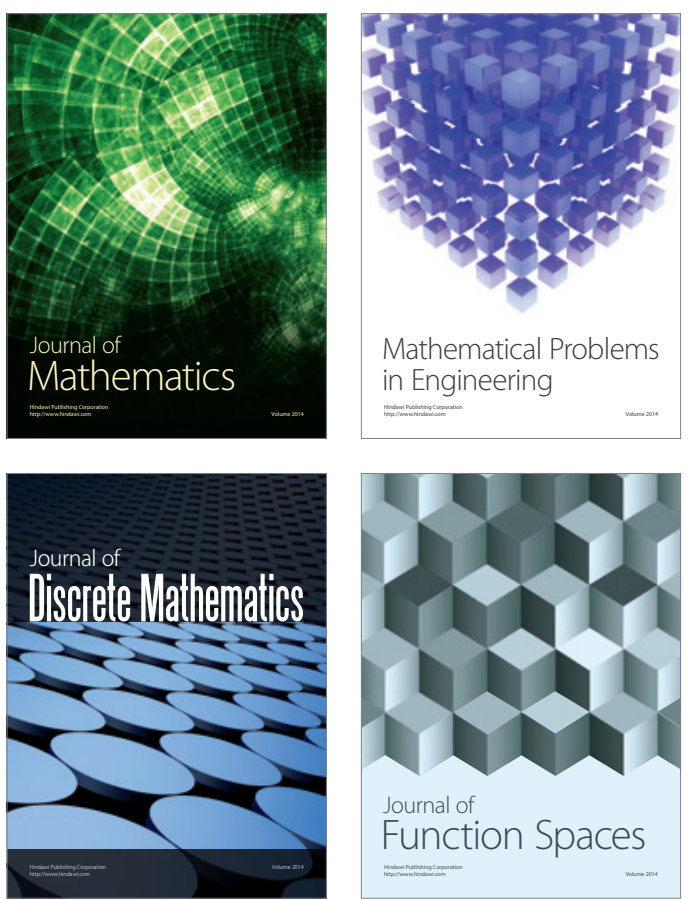

Mathematical Problems in Engineering
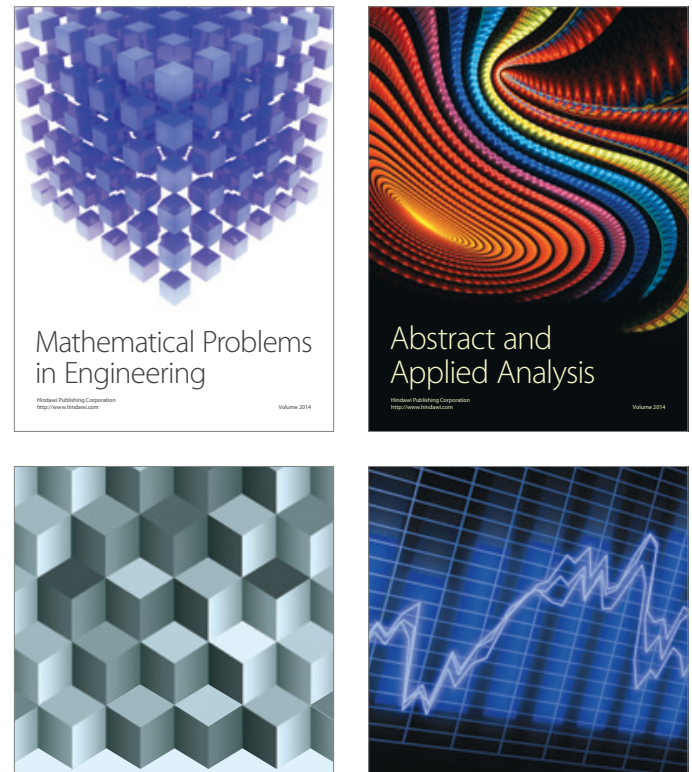

Journal of

Function Spaces

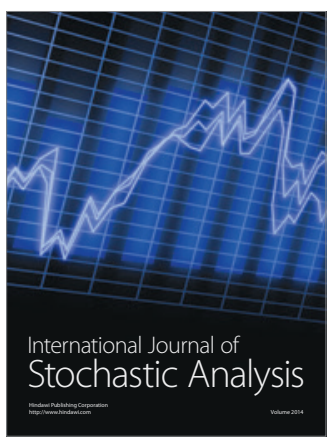

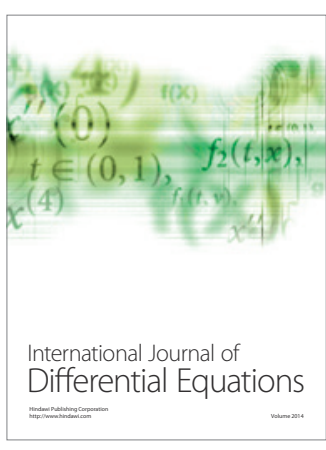
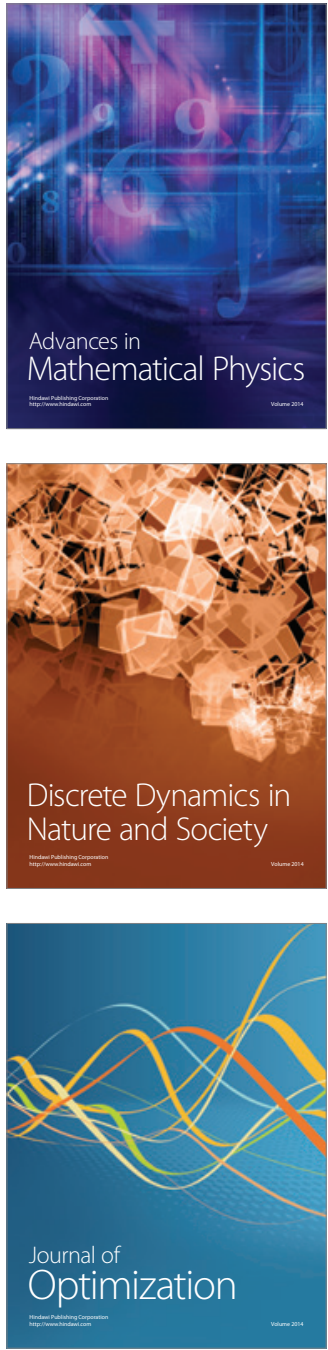